\title{
Fracture of 2D Triaxially Braided Carbon Fiber Composites and Resin Effects on the Energy Absorption
}

\author{
Amit G. Salvi ${ }^{1}$, Anthony M. Waas ${ }^{2}$ \\ Department of Aerospace Engineering \\ The University of Michigan \\ Ann Arbor, MI 48109-2140, USA \\ Ari Caliskan ${ }^{3}$ \\ Vehicle Design R\&A Department \\ Ford Motor Company \\ Dearborn, MI 48121, USA
}

\begin{abstract}
Results from an experimental program to investigate the propagation of damage in $2 \mathrm{D}$ triaxially braided carbon fiber textile composites (2DTBC) under static conditions are reported. A methodology is presented in which classical concepts from fracture mechanics are generalized to address damage growth in an orthotropic and heterogeneous structural material. Along with results from the experimental program, a novel numerical technique that employs ideas from cohesive zone modeling and implemented through the use of finite element analysis is also presented. The inputs that are required to implement such a discrete cohesive zone model (DCZM) are identified. Compact tension specimen (CTS) fracture tests were carried out by loading 2DTBC coupons cyclically and monotonically. Load and load point displacement were measured. The crack initiation, propagation and crack path history was recorded using high resolution digital photography. The measurements were used to extract the fracture energy $\left(G_{I C}\right)$ as a function of crack tip position. Notched Tension tests were carried out to measure the maximum stress in the composites, which provides the cohesive strength $\left(\sigma_{c}\right)$ of these composites. The material constants so obtained and the DCZM modeling strategy were independently verified by conducting single edge notched bend (SENB) fracture tests using a modified three-point bend test fixture. The experimental and numerical analyses were carried out for two different types of $2 \mathrm{DTBC}$ made from two different resin systems to confirm the usefulness of the proposed methodology.
\end{abstract}

\section{Introduction}

Textile fiber composites are finding increased use as a structural material in a variety of aerospace and automotive industrial applications. An appealing property of such composites is their high-energy absorption capability under compressive crush loads, on a per unit weight basis. Due to the high degree of interweaving of fiber tows in the material microstructure, damage accumulation through distributed microcracking of the matrix is preferred to the coalescence and growth of cracks in the composite at fracture; the microstructure presents "obstacles" to the propagation of a macroscopic crack. The resulting increase in toughness, the flexibility afforded in designing the textile architecture for desirable stiffness in a given application, and net-shape manufacturability are all advantages of textile fiber composites. Stiffer and tougher materials can be designed with textile composites. The replacement of metal structural parts by equivalent composite structural parts can lead to weight savings in excess of $30 \%$. These savings translate directly to reduced operational costs of an aerospace vehicle.

\footnotetext{
${ }^{1}$ Research Assistant, Dept. of Aerospace Engineering, Univ. of Michigan, Ann Arbor, MI-48105

${ }^{2}$ Professor, Dept. of Aerospace Engineering, Univ. of Michigan, Ann Arbor, MI-48105

${ }^{3}$ Research Engineer, Vehicle Design and R\&A Dept. Ford Motor Company, Dearborn, MI 48121
} 
Even though a strong case can be made for utilizing composite structural parts in several areas of a load bearing structure, the requirement to demonstrate structural integrity and damage tolerance (SIDT) necessitates a fundamental understanding of the mechanical response, damage tolerance and damage growth of a load bearing composite structure. While a considerable amount of literature is present on addressing damage growth in the form of delamination crack growth, lying parallel to the interfaces of the different layers of a composite, much less is known or understood about damage propagation when a crack or damage in the form of a crack is present through the thickness of a composite structure. The influence of such a crack on the load bearing ability of a homogeneous and isotropic material has received considerable attention in the past; however, a similar effort at resolving issues in a non-homogeneous and macroscopically orthotropic structure is still a problem that requires resolution. Because of the different length scales associated with the microstructure of a composite material and the resulting composite structure, a multitude of failure mechanisms can be operative simultaneously, leading to a very complex picture associated with the manner in which damage progresses in a composite structure. Even though, an initial, sharp, through the thickness crack can be present in a composite structure, as soon as damage accumulates at the initial crack tip (this can be in the form of matrix microcracking), crack blunting and spreading of such damage (this can involve tow separation and ply delamination, in addition to matrix cracking) in the highly stressed areas around this initial crack occurs. When this initial crack starts to grow, a zone of material that is considerably larger than that would be found in a monolithic material, in the form of a band is seen to grow along with this crack like feature. That is, there is no clean "crack" that can be identified as in a monolithic material like metal. Instead, a diffused zone of damage is seen to advance. A large toughness is associated with this damage growth, largely influenced by the tows that bridge the damage zone, providing additional resistance for primary crack growth. This additional resistance is very desirable and is a major contributor to the increased toughness of these 2DTBC.

Linear elastic fracture mechanics (LEFM) has been developed and implemented within FE codes to study a variety of fracture problems. Essential to the success of LEFM approaches is the requirement of a small process zone ahead of the crack tip, [1]. Depending on the size of this process zone, LEFM ideas can be extended to include plasticity dominated effects, but beyond a certain size of this process zone, other modeling strategies such as the cohesive zone modeling approach have found favor in a wide variety of fracture problems. Among fracture parameters, the strain energy release rate is used increasingly in conjunction with LEFM. It can be computed by the virtual crack closure technique (VCCT), [2], in conjunction with FE analysis. The application of VCCT is predicted on the requirement of a pre-existing crack with a sharp and neat tip within a material for crack initiation and conditions of small scale yielding to hold. With negligible material non-linearity at the crack tip (small process zone size), LEFM based approaches have been proven to be effective in predicting crack initiation and subsequent growth [1-6].

In many cases of crack growth in composite materials and structures made of other quasi-brittle materials, the process zone size may be larger than any characteristic length scale in the problem leading to situations where the basic tenets of LEFM cease to hold [7]. Several mechanisms can contribute to this situation. Micro-cracking, fiber bridging, coalescence of voids and other mechanisms at the microstructural scale can give rise to a process zone that is considerably larger than what is required for assumptions of LEFM to hold. A new length scale, $l^{*}$, emerges that is related to a characteristic elastic modulus E, fracture toughness $\Gamma$ and cohesive strength, $\sigma_{\mathrm{c}}$, defined as, $l^{*}=\frac{E \Gamma}{\sigma_{c}^{2}}$. If $l^{*}$ is larger than any characteristic length scale in the problem, then, cohesive zone models (CZM) become an indispensable tool for analysis [8-13]. The origin of the CZM can be traced back to the Barenblatt-Dugdale (BD) model that was introduced for fracture in ductile metals, with the concept that stress within the zone ahead of the crack tip is limited by the material yield strength and thus generates a plastic strip of constant stress ahead of the intended crack path [1]. The CZM assumes that a cohesive damage zone (in this zone stress can decrease with increasing opening and/or shearing) develops ahead of the crack path without necessarily requiring that the stress be constant within this zone. Therefore, the CZM is a broader generalization of the BD model. 
In order to implement a CZM in its simplest form, two parameters are required: a fracture toughness (or energy) and a cohesive strength. The choice of these parameters and how they are measured and/or calibrated depends on the problem that is being addressed. In general, the CZM parameters are "system" parameters and are related to the material system that is being studied. The fracture toughness can be obtained from coupon level tests of the material system under study. This measured toughness value in conjunction with a CZM/FE simulation of the test can be used to back out the cohesive strength. Alternatively, both the toughness and strength can be measured from coupon level tests for subsequent use in prediction of crack growth in other structural configurations. In the CZM, an existing crack starts to grow when the stress at the crack tip attains the cohesive strength and when there is sufficient energy supplied from the system to create new cracked area associated with the advancing crack. Thus, unlike LEFM, which requires one parameter, a CZM strategy requires two parameters for predicting crack growth. A cohesive law combines fracture energy and cohesive strength to describe the resistance offered to crack advancement within the cohesive zone. Various postulated forms of cohesive laws (such as triangular, exponential, trapezoidal, multi-section, etc.) have been attempted in conjunction with CZM [14-18]. These studies, however, have shown that the form of the phenomenological cohesive law is less important than the well-posed implementation when CZMs are used with FE analysis.

This paper is an attempt to develop a procedure by which damage growth in the form of a crack like zone, emanating from an initial crack like flaw, in heterogeneous and orthotropic materials can be characterized. In addition to characterizing the $2 \mathrm{DTBC}$ as an orthotropic elastic (or elastic-plastic) medium, additional parameters that are necessary for implementing a DCZM $[5,7]$ are identified and quantified. The procedure is validated by performing independent experimental measurements on a SENB configuration and using the DCZM to predict the response of the SENB tests during crack growth. Further validation is carried out by considering $2 \mathrm{DTBC}$ made from two different matrix materials.

\section{Compact Tension Specimen (CTS) Fracture Tests on 2DTBC}

\section{A. Specimen Architecture of 2DTBC:}

Figure 1 show the architecture of a $0 / \pm 45^{\circ} 2 \mathrm{DTBC}$ used in the present study. Eight braided composite fiber mats (axial tows consisting of 80,000 fibers and biased tows consisting of 12,000 fibers) were stacked together and matrix is then infused. Two types of composites were prepared by using two different resin systems, but with the same fiber tow architecture. Ashland Hetron 922 vinyl-ester and Epon 862 epoxy resin were used as resins for these composites. The $2 \mathrm{DTBC}$ is modeled as a homogenous orthotropic elastic-plastic material for the modeling studies. The four principal material elastic properties, denoted as $E_{11}, E_{22}, v_{12}$ and $G_{12}$, were measured by using ASTM (American Society for Testing and Materials) specified standard material property tests. Dog bone shaped specimens were used to measure elastic moduli $\left(E_{11}\right.$ and $\left.E_{22}\right)$ and Poisson's ratio $\left(v_{12}\right)$, and, the Iosipescu shear test was performed to obtain the shear modulus $\left(\mathrm{G}_{12}\right)$. Table 1 summarizes the effective elastic mechanical properties of Epon and Hetron specimens.

\section{B. Experimental Procedure for CTS tests:}

Compact Tension Specimen (CTS) fracture tests were carried out on 2DTBC Hetron and 2DTBC Epon matrix composites to measure the fracture energy of these composites. CTS specimens, 3in by $4.5 \mathrm{in}$ $(76.2 \mathrm{~mm}$ by $114.3 \mathrm{~mm})$, were cut and a 2 in $(50.4 \mathrm{~mm})$ long notch was introduced as shown in Figure 2 (a). A sharp knife-edge was used to introduce an initial crack as shown in figure 2 (b). The load was applied through pins as shown in Figure $2(\mathrm{c})$. Load $(\mathrm{P})$ and load point displacement $(\Delta)$ were measured during the experiment. Crack initiation and propagation were captured using a Kodak high resolution digital camera. Specimens were loaded on a hydraulically activated MTS machine at a rate of $0.0004 \mathrm{in} / \mathrm{sec}(0.01 \mathrm{~mm} / \mathrm{sec})$. Experiments were carried out on both Epon and Hetron 2DTBC.

Two types of loading patterns were used to load the specimens. In first set of tests, specimens were loaded monotonically until failure. In the second set of tests, the specimens were loaded and unloaded cyclically in a controlled manner so that the "primary crack" grows in each of the cycles. This was done so 
that the elastic energy associated with the fracture can be separated (by unloading the specimens) from the total fracture energy. In cyclic loading, a specific loading pattern was adopted. Information from the initial monotonically loaded fracture specimens was used to determine the primary crack initiation load and the corresponding load point displacement $\left(\Delta_{\mathrm{c}}\right)$ as shown in Figure 2 (d). Subsequently, specimens were loaded beyond $\Delta_{\mathrm{c}}$ to $\Delta$, to initiate and extend the primary crack. Specimens were then unloaded to a certain point $\Delta_{U}$ where the load drops to zero. Once $\Delta_{U}$ is reached, the specimen is again loaded up to $\Delta_{2}$ and unloaded to $\Delta_{U}$. This cycle is repeated several times as shown in figure 2(d). Figure 2 (e) shows the applied displacement as a function of time. Figure 2(f) shows a typical load vs. load point displacement behavior for a cyclic loading (for Hetron specimens).

\section{Experimental observations:}

Figure 3 (a) shows the load vs. load point displacement behavior of a monotonically loaded Hetron specimens and Figure 3 (b) shows the load vs. load point displacement behavior for Epon specimens. Initially the load was seen to increase with load point displacement. Subsequent to crack growth initiation, the load was still rising due to the formation of the bridging zone, which offers resistance to crack growth. A peak load is reached and the failure of the bridging fiber tows leads to a post-peak softening behavior, as indicated in these figures.

In the cyclic tests, the crack propagation during loading was captured by a high resolution digital camera. Figure 3 (c) shows an image of crack opening during the CTS fracture tests. Crack extension during each loading cycle was measured. The primary crack initiates and gets arrested by the biased braids which are at angle of $45^{\circ}$ to the direction of crack path. As discussed earlier, extensive damage is associated with the advancing primary crack. Because the state of stress surrounding the damaged material is expected to be elevated compared to the areas remote from the crack front, the damage region surrounding the advancing crack is diffused and there is a large region of bridging that develops as the specimen is continued to load. What is remarkable is the "path independency" that is displayed by these specimens. For a given load point displacement $\Delta$, the values of applied load that is required to attain such a displacement is indistinguishable between the cyclic tests and the monotonically loaded tests. However, the cyclic tests reveal a considerable amount of hysteresis.

As the initial crack begins to advance, it forms a bridging zone as shown in Figure 3 (d). This bridging zone consists of biased braids that are at $45^{\circ}$ to the direction of (axial tows) crack propagation. As the crack progresses, the bridging zone becomes larger. However, once a critical length of the bridging zone is formed, it stays constant and travels with the advance in the crack propagation. Once this bridging zone approaches the vicinity of the load application point, it starts to fail (biased braids) thus leading to drop in the overall load. As the crack bridging diminishes, due to unstable crack growth in the specimen, the overall load drop sharply (refer Figure 3 (a)). Figure 3 (e) shows an image of crack opening and bridging zone formation.

Figure 4 (a) and Figure 4 (b) shows the crack tip positions at the end of each load-unload cycle for Hetron and Epon specimens respectively. The crack initiation and progression differs somewhat, as the microstructure for each specimen is different. The initial crack position with respect to the braid architecture is not exactly the same for deferent specimens.

Fracture energy was measured by calculating the area under each loading-unloading curve, which represents the energy lost in fracture of the specimen or the crack propagation during that cycle. For each test, the area under each loop of the P- $\Delta$ response was calculated. The local dissipated energy per cycle is obtained as,

$$
G_{I c}=\frac{\operatorname{Area}(P \Delta)_{i}}{2 C_{i} t}
$$

where:

Area $(\mathrm{P} \Delta)_{\mathrm{i}}=$ Area under $\mathrm{i}^{\text {th }}$ loop

$\mathrm{C}_{\mathrm{i}}=$ Crack Extension during $\mathrm{i}^{\text {th }}$ loading

$\mathrm{t}=$ Thickness of the specimen 
Figure $4(\mathrm{c})$ and Figure $4(\mathrm{~d})$ shows the fracture energy $\left(\mathrm{G}_{\mathrm{Ic}}\right)$ as a function of "primary crack" position. It can be observed that the fracture energy as a function of crack position is not smooth and non-uniform for each specimen. However, an examination of the results from the monotonic tests sheds more light on the observed test data from the cyclic tests.

The monotonic loading tests consisted of loading the specimens continuously until failure. In these tests, the crack position was measured during the entire envelope of the loading. Figure 4 (e) and Figure 4 (f) shows the crack position vs. time for the monotonically loaded Hetron and Epon specimens respectively. Figure 4 (g) shows the behavior of specimen compliance vs. time for these tests. It was observed that the compliance is almost constant initially. As the crack grows, the specimen becomes more compliant due to the failure of the fiber bridging zone, which diminishes the resistance to further crack advance (post peak load behavior).

The data from the monotonic tests were analyzed in two different ways. In the first, the entire crack length was used to obtain an "averaged" fracture energy for advancing the crack by the entire growth length. This energy is calculated by considering the entire area under the work input curve (P- $\Delta$ curve). In a second method, since the instantaneous crack advanced position is known, it is assumed that the work input from the loading is entirely dissipated as damage energy associated with crack advancement. Thus, the fracture energy, obtained by measuring crack extension and area under the P- $\Delta$ curve corresponding to that crack extension was calculated:

$$
G_{I c}=\frac{\operatorname{Area}(P \Delta)_{i}}{2 \cdot a_{i} \cdot b}
$$

where,

Area $\left(\mathrm{P} \Delta_{\mathrm{i}}\right)=$ area under $\mathrm{P}-\Delta$ curve for crack extension up to crack length $\mathrm{a}_{\mathrm{i}}$,

$\mathrm{a}_{\mathrm{i}}=$ crack extension,

$\mathrm{b}=$ thickness of the specimen

Figure 4 (h) and Figure 4 (i) shows plots of fracture energy $\left(\mathrm{G}_{\mathrm{Ic}}\right)$ as a function of crack growth for Epon and Hetron specimens. It was observed that the fracture energy increases with the formation and propagation of crack bridging zone. The fracture energy then plateaus as the bridging zone translates and then drops as soon as the bridging zone starts to diminish.

\section{Cohesive Strength $\left(\sigma_{c}\right)$ :}

The value of cohesive strength $\left(\sigma_{c}\right)$ that is to be used in the cohesive law of the DCZM can be related to the transverse strength of the composite (the strength in a direction that is normal to the crack advancement direction). Braided specimens, 2in x 7in $(50.8 \mathrm{~mm} \times 177.8 \mathrm{~mm})$ long, were cut and a notch of $0.5 \mathrm{in}(12.7 \mathrm{~mm})$ was introduced on both the edges, in the center of the specimen as shown in Figure 5 . The specimens were loaded in tension in the direction perpendicular to the direction of the axial tows. The axial stress, based on the net section area, and load point displacements were measured in the experiment. The average transverse strength $\left(\sigma_{c}\right)$ of the Hetron composite was approximately $66 \mathrm{~N} / \mathrm{mm}^{2}\left( \pm 3 \mathrm{~N} / \mathrm{mm}^{2}\right)$. Thus, using the measured values of transverse strength $\sigma_{c}$, and fracture energy, $\mathrm{G}_{\mathrm{IC}}(\Delta a)$, a full description of the DCZM cohesive law can be obtained. The average transverse strength $\left(\sigma_{c}\right)$ of the Epon composites was found to be $62 \mathrm{~N} / \mathrm{mm}^{2}\left( \pm 3 \mathrm{~N} / \mathrm{mm}^{2}\right)$.

\section{Discrete Cohesive Zone Model (DCZM)}

A Discrete Cohesive Zone model (DCZM) was developed [3] that simulates the fracture of CTS configuration. The central idea of DCZM is to treat material separation as being represented by a discrete bed of springs that communicate between opposite node pairs on the faces of material that needs to be decohered. A nonlinear "spring type" discrete 1D element was placed between interfacial node pairs to 
model cohesive interactions between surfaces along the crack path as shown in Figure 6 (a). The 2DTBC was treated as an elastic plastic orthotropic homogenized material for modeling. The plasticity of the specimen was described using a one parameter plasticity model [7]. The fracture tests were simulated by using the DCZM based interface elements which were implemented into ABAQUS ${ }^{\circledR}$ by using a user element subroutine UEL.

In the present study, a triangular cohesive law was used as shown in Figure 6 (b). Based on the energy required to advance the primary crack, we have,

$$
\frac{1}{2} \sigma_{c} \delta_{m}=G_{I C}
$$

where $\mathrm{G}_{\mathrm{IC}}$ is the fracture energy of the material that is to be measured through the CTS tests. $\delta_{\mathrm{m}}$, and $\sigma_{\mathrm{c}}$ are the maximum nodal opening and the critical cohesive stress, respectively. In this study, we choose $\sigma_{\mathrm{c}}$ as the cohesive parameter. The numerical value of cohesive stress $\left(\sigma_{c}\right)$ was determined by carrying out tension tests on notched dog-bone specimens, as presented earlier, and $\delta_{\mathrm{m}}$ is calculated from Equation (3). The critical value for the cohesive force in the DCZM element is

$$
F_{c}=\sigma_{c} B \Delta a=\frac{2 G_{I C} B \Delta a}{\delta_{m}}
$$

where, $B$ is the out-of-plane thickness of the specimen. Since the spacing of the DCZM element depends on the coordinates of the nodes, $F_{c}$ depends on the mesh size (note $\sigma_{c}$ is independent of element spacing). The critical opening $\left(\delta_{c}\right)$ is calculated by

$$
\delta_{c}=\frac{F_{c}}{K_{\bar{y}}}
$$

where $K_{\bar{Y}}$ is the initial stiffness of the DCZM element which is selected to be a very high value relative to the stiffness of the bridged material.

To apply the triangular cohesive law, when $\delta \leq \delta_{c}, K_{\bar{Y}}$ was set to be a very large number to ensure that the crack is initially closed. In numerical implementation, this value usually is chosen to be three orders of magnitude larger than the major Young's modulus of the specimen. When $\delta_{c}<\delta<\delta_{m}$, the softening part of the cohesive zone, $K_{\bar{Y}}$ is determined as

$$
K_{\bar{Y}}=-\frac{F_{c}}{\delta_{m}-\delta_{c}}
$$

Finally, when $\delta \geq \delta_{m}$, the DCZM element fails completely, and $K_{\bar{Y}}=0$.

Constant fracture energy $\left(\mathrm{G}_{\mathrm{IC}}\right)$ value of $57 \mathrm{~N} / \mathrm{mm}$ was used to simulate the CTS fracture tests for Hetron specimens. Figure 6 (c) shows the comparison of experimental and DCZM simulation of P- $\Delta$ response. Similarly, constant fracture energy $\left(\mathrm{G}_{\mathrm{IC}}\right)$ value of $41 \mathrm{~N} / \mathrm{mm}$ was used to simulate the CTS fracture tests for Epon specimens and the P- $\Delta$ behavior is shown in Figure 6(d). It was found that the DCZM results agree well with the experimental results.

\section{Single Edge Notch Bend (SENB) Fracture Tests on 2DTBC - Validation of the Proposed Scheme}

\section{A. Experimental Procedure:}

To verify the methodology of measuring the fracture energy $\left(\mathrm{G}_{\mathrm{IC}}\right)$ through CTS configuration, cohesive strength $\left(\sigma_{\mathrm{c}}\right)$ by notched tension tests and modeling the fracture behavior through DCZM implementation, an independent set of fracture tests were carried out using a modified single edge notch bend (SENB) specimen [19]. Figure 7 (a) shows the configuration and dimensions of the specimen. Hetron and Epon specimens were monotonically loaded on a hydraulically activated MTS machine. The specimen 
was secured on top of two steel rollers and loaded using a top-loading pin attached to the crosshead of a MTS servo hydraulic loading frame at a displacement rate of $0.0004 \mathrm{in} / \mathrm{sec}(0.01 \mathrm{~mm} / \mathrm{sec})$. A high resolution (7.50Megapixel) camera was used to take images at one-second intervals to keep track of the crack trajectory during the loading history. The applied load was measured using a load cell attached to the MTS test frame and the load point displacement was measured using an LVDT. Figure 7 (b) shows the test set-up for SENB fracture tests.

\section{B. Experimental Observations:}

The P- $\Delta$ behavior for the Hetron specimens is shown in Figure 7 (c). Figure 7 (d) shows the P- $\Delta$ behavior for the Epon specimens. Figure 7 (e) shows the crack tip positions during the monotonic loading of Hetron specimens. Similar to the monotonic CTS fracture tests, the fracture energy was calculated by measuring crack length and the area under the P- $\Delta$ curve. The differences in P- $\Delta$ behavior between the Hetron and Epon composites are clear from these figures. The Hetron composites show a diffused and smoother transition in the post-peak regime, while in the Epon specimens, failure quite abrupt beyond the peak load.

From these figures, it could be observed that the fracture energy of Hetron specimens was higher than that of the Epon specimens. Due to smaller fracture energy values, the energy absorption performance of the Epon specimens was poorer than that of Hetron specimens i.e. in the post peak load regime the Hetron specimens absorb more energy than Epon specimens. Upon close inspection of the specimens it was found that the Hetron specimens show a larger damage zone than that of the Epon specimens as shown in Figure 7 (f). The extensions within the bridging zone are much larger in the Hetron samples leading to larger crack opening displacements. As the primary crack grows in the specimens, the energy is dissipated by matrix cracking, breaking of the fiber bridging tows, and fiber matrix separation. Hetron specimens show larger amounts of fiber bridging, and a large amount of secondary cracking which are a result of elevated stresses in the vicinity of the primary crack. Epon specimens show very little fiber bridging and almost negligible breaking in the fiber bridging zone. Also, the area adjacent to the primary crack shows very little matrix damage. These observations are reflected in the measurements that indicate Hetron 2DTBC to be a better energy absorber than Epon 2DTBC

\section{Discrete Cohesive Zone Model for SENB Tests:}

A Discrete Cohesive Zone Model for the SENB configuration was developed to validate the usefulness of the DCZM. A fracture energy value of $57 \mathrm{~N} / \mathrm{mm}$, which was obtained from the CTS simulation in conjunction with the CTS tests, was used for the SENB simulation. The SENB Model was created with three mesh densities: Case $A=1610$ elements, case $B=6570$ elements and case $C=26280$ elements as shown in Figure 8(a). Figure 8 (b) shows the prediction of the DCZM for SENB fracture tests for Hetron specimens. The DCZM predictions are very close to the experimental results. The DCZM model was modified to include plasticity of the 2DTBC by writing a UMAT subroutine that models the 2DTBC through a one parameter plasticity model [20]. The plasticity parameter $\mathrm{a}_{66}$ was measured by carrying out off-axis compression tests [7,21, and 22]. $\mathrm{a}_{66}$ for Hetron specimens was found to be 1.2. Results obtained with the inclusion of plasticity are shown in Figure 8 (c). It was found that including plasticity improved the results for the P- $\Delta$ prediction between experiment and simulation. Figure 8(d) shows the DCZM prediction for Epon specimens under SENB fracture. It was observed that the DCZM technique predicts fracture behavior very well for Epon specimens, which has a fracture energy of $41 \mathrm{~N} / \mathrm{mm}$, cohesive strength of $62 \mathrm{~N} / \mathrm{mm}^{2}$ and plasticity parameter $\mathrm{a}_{66}=1.1$.

\section{Concluding Remarks}

A generalized methodology to predict fracture in non-homogeneous and orthotropic 2D triaxially braided composites is presented. Static fracture tests were carried out on carbon fiber braided composites specimens by cyclically and monotonically loading notched compact tension specimens (CTS). Load and load point displacement and the crack propagation during the loading were measured. In cyclic loading, 
fracture energy was calculated for each cycle by using this information. It was found that this method gives non-uniform fracture energy as a function of crack position, which could not be effectively used for numerical analysis, thus a different approach was needed to measure the fracture energy. Fracture tests were then carried out by loading the CTS specimens monotonically to failure. Fracture energy was calculated by measuring the area under the P- $\Delta$ curve and then dividing by the total crack extension. This approach gives the fracture energy as a smooth function of crack position, essentially averaging the crack growth path over several lengths of the scale of non-homogeneity in these classes of material.

To simulate the fracture behavior of CTS tests, a Discrete Cohesive Zone Model was developed. Geometry, material properties, fracture energy and cohesive strength values were used as inputs in the DCZM. This DCZM then can be used to predict fracture behavior in other configurations of this material. A constant fracture energy value of $57 \mathrm{~N} / \mathrm{mm}$ obtained from the monotonic loading fracture tests and cohesive strength of $66 \mathrm{~N} / \mathrm{mm}^{2}$ were used to simulate the fracture under CTS configuration. Similarly a constant fracture energy value of $41 \mathrm{~N} / \mathrm{mm}$ and cohesive strength of $62 \mathrm{~N} / \mathrm{mm}^{2}$ were used to simulate fracture of Epon specimens. It was found that the simulation results agree well with the experimental P- $\Delta$ behavior. These tests, thus, establish a means by which fundamental material data can be obtained for simulating fracture in other configurations for this orthotropic and non-homogeneous material.

The DCZM was used to predict the response behavior of Hetron and Epon composites by carrying out SENB tests. The SENB test results were repeatable in terms of the P- $\Delta$ response. A constant fracture energy value of $57 \mathrm{~N} / \mathrm{mm}$ for Hetron and $41 \mathrm{~N} / \mathrm{mm}$ for Epon obtained from the monotonic CTS fracture tests was used to simulate the fracture under SENB configuration. These fracture energy values in conjunction with cohesive strength $\left(\sigma_{c}\right)$ values of $66 \mathrm{~N} / \mathrm{mm}^{2}$ for Hetron and $62 \mathrm{~N} / \mathrm{mm}^{2}$ for Epon provided very good agreement with measurement for the P- $\Delta$ response of the SENB tests.

The authors are grateful for the financial sponsorship of the Automotive Composites Consortium, Energy Management Working Group, and the Department of Aerospace Engineering, University of Michigan. The authors acknowledge that this research was supported, in whole or in part, by Department of Energy cooperative agreement no. DE-FC05-95OR22363. Such support does not constitute an endorsement by the Department of Energy of the views expressed herein.

\section{References}

1. Hertzberg, J. Deformation and fracture mechanics of engineering materials, text, Wiley, 1983.

2. Xie D and Biggers, Jr. SB., "Strain energy release rate calculation for a moving delamination front of arbitrary shape based on virtual crack closure technique, Part I: Formulation and Validation", Engineering Fracture Mechanics, 2006; 73: 771-785. See also, Xie D and Biggers, Jr. SB., "Progressive crack growth analysis using interface element based on the virtual crack closure technique", Finite Elements in Analysis and Design, 2006; 42(11):977-984.

3. Xie D and Biggers, Jr. SB., "Strain energy release rate calculation for a moving delamination front of arbitrary shape based on virtual crack closure technique, Part II: Sensitivity Study on Modeling Details", Engineering Fracture Mechanics, 2006; 73:786-801.

4. Xie D, Waas AM, Shahwan KW, Schroeder JA and Boeman RG, "Computation of energy release rates for kinking cracks based on virtual crack closure technique", CMES-Computer Modeling in Engineering \& Sciences, 2004; 6:515-524.

5. Xie D, Waas AM, "Discrete cohesive zone model for mixed-mode fracture using finite element analysis", Engineering Fracture Mechanics 2006; 73:1783-1796.

6. Xie D, Chung J, Waas AM, Shahwan KW, Schroeder JA, Boeman RG, Kunc V, and Klett LB, "Failure analysis of adhesively bonded structures: from coupon level data to structure level predictions and verification", International Journal of Fracture, 2005; 134:231-250.

7. Xie D, Salvi AG, Sun C, Waas AM and Caliskan, "Discrete cohesive zone model to simulate static fracture in 2-D triaxially braided carbon fiber composites", Journal Composite Materials, 2006; 40:2025-2046.

8. Pietruszczak S and Mroz Z, "Finite element analysis of deformation of strain softening materials", International Journal for Numerical Methods in Engineering, 1981; 17:327-334. 
9. Ungsuwarungsri T and Knauss WG, "The Role of Damage-Softened Material Behavior in the fracture of composites and adhesives", International Journal of Fracture, 1987; 5:221-241. See also Ph.D. thesis, 1985, Aeronautics Department, Caltech, Pasadena, CA.

10. Tvergaard V and Hutchinson JW, "The relation between crack growth resistance and fracture parameters in elastic-plastic solids", Journal of the Mechanics and Physics of Solids, 1992; 40:13771397.

11. Schellekens JCJ and de Borst R, "On the numerical integration of interface elements", International Journal for Numerical Methods in Engineering, 1993; 36: 43-66.

12. Xu XP and Needleman, "A. Numerical simulation of fast crack growth in brittle solids", Journal of the Mechanics and Physics of Solids, 1994; 42:1397-1434.

13. Camacho GT and Ortiz M, "Computational modeling of impact damage in brittle materials", International Journal of Solids and Structures, 1996; 33:2899-2938.

14. Reedy ED, Mello FJ and Guess TR, "Modeling the initiation and growth of delaminations in composite structures, Journal of Composite Materials, 1997; 31: 812-831.

15. Pandolfi A, Krysl P and Ortiz M, "Finite element simulation of ring expansion and fragmentation: The capturing of length and time scales through cohesive models of fracture", International Journal of Fracture, 1999; 95:279-297.

16. Espinosa HD, Zavattieri PD and Dwivedi SK, "A finite deformation continuum discrete model for the description of fragmentation and damage in brittle materials", Journal of the Mechanics and Physics of Solids, 1998; 46:1909-1942.

17. Zavattieri PD, Raghuram PV and Espinosa HD, "A computational model of ceramic microstructures subjected to multi-axial dynamic loading. Journal of the Mechanics and Physics of Solids 1002; 49:2768.

18. Li S, Thouless MD, Waas AM, Schroeder JA and PD Zavattieri. Mixed-mode cohesive-zone models for fracture of an adhesively bonded polymer-matrix composite", Engineering Fracture Mechanics, 2006; 73:64-78.

19. Salvi A.G, Chung J, Waas AM and Caliskan A, "Strain rate effects on unidirectional carbon fiber composites", AIAA journal, 2003; 41(10): 2020-2028.

20. Sun CT, Chen JL, "A simple flow rule for characterizing nonlinear behavior of fiber composites", Journal of Composite Materials, 1989, 23:1009-1020.

21. Salvi AG, Waas AM, Caliskan A, "Rate dependent compressive behavior of unidirectional carbon fiber composites", Polymer Composites, 2004; 25(4):397-406.

22. Salvi AG, Waas AM, Caliskan A "Specimen size effects in the off-axis compression test of unidirectional Rate dependent compressive behavior of unidirectional carbon fiber composites", Composite Science \& Technology, 2004, 64; 83-97. 


\begin{tabular}{|c|c|c|}
\hline Material Properties & $\begin{array}{c}\text { Hetron } \\
(\mathrm{GPa})\end{array}$ & $\begin{array}{c}\text { Epon } \\
(\mathrm{GPa})\end{array}$ \\
\hline & & \\
$\mathrm{E}_{11}$ & $68.5 \pm 5.4$ & $108.5 \pm 7.2$ \\
$\mathrm{E}_{22}$ & $10.7 \pm 2.1$ & $16.1 \pm 2.8$ \\
$\mathrm{G}_{12}$ & $7.5 \pm 1.1$ & $12.1 \pm 2.4$ \\
$v_{12}$ & 0.36 & 0.34 \\
\hline
\end{tabular}

Table 1. Material Properties for 2DTBC Hetron and Epon specimens

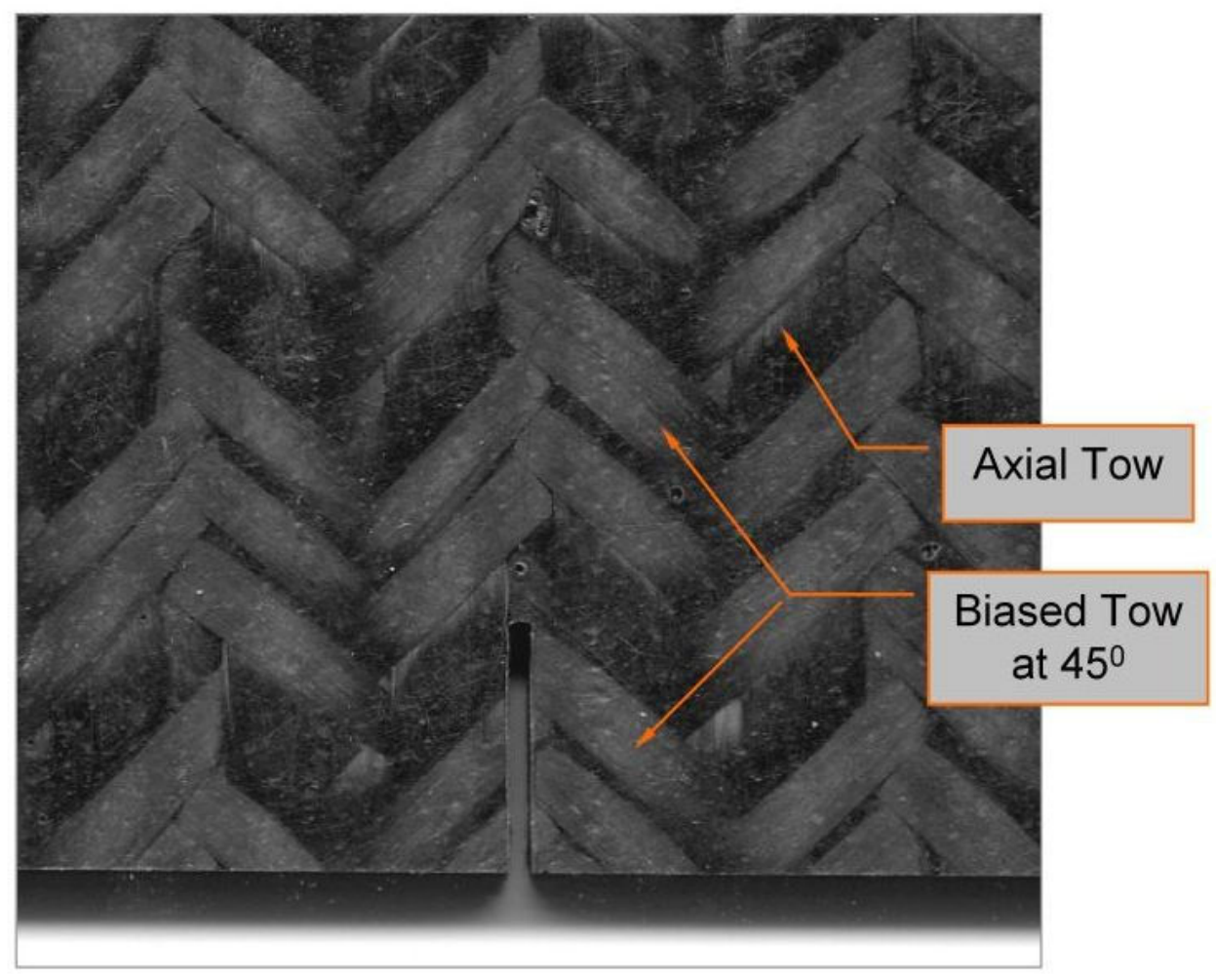

Figure 1: Architecture of 2DTBC 


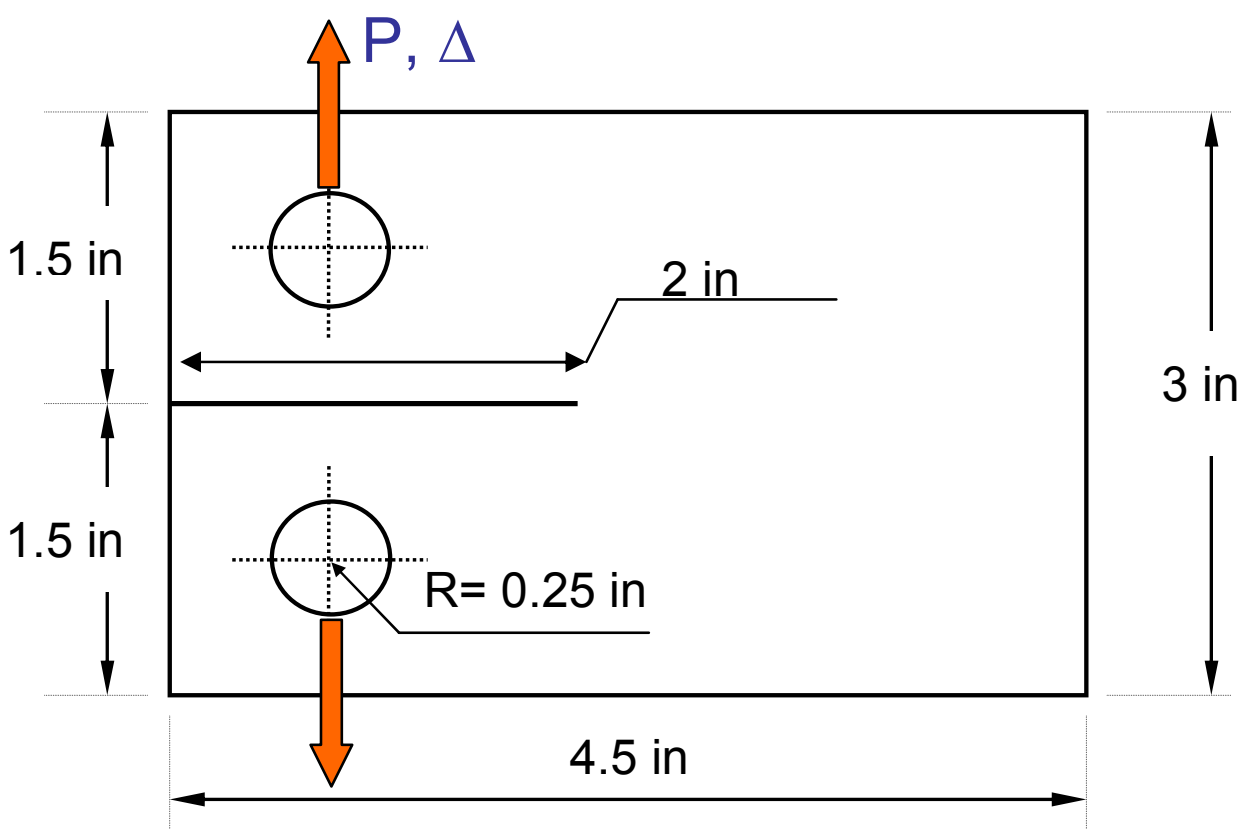

Figure 2 (a): Compact tension specimen configuration

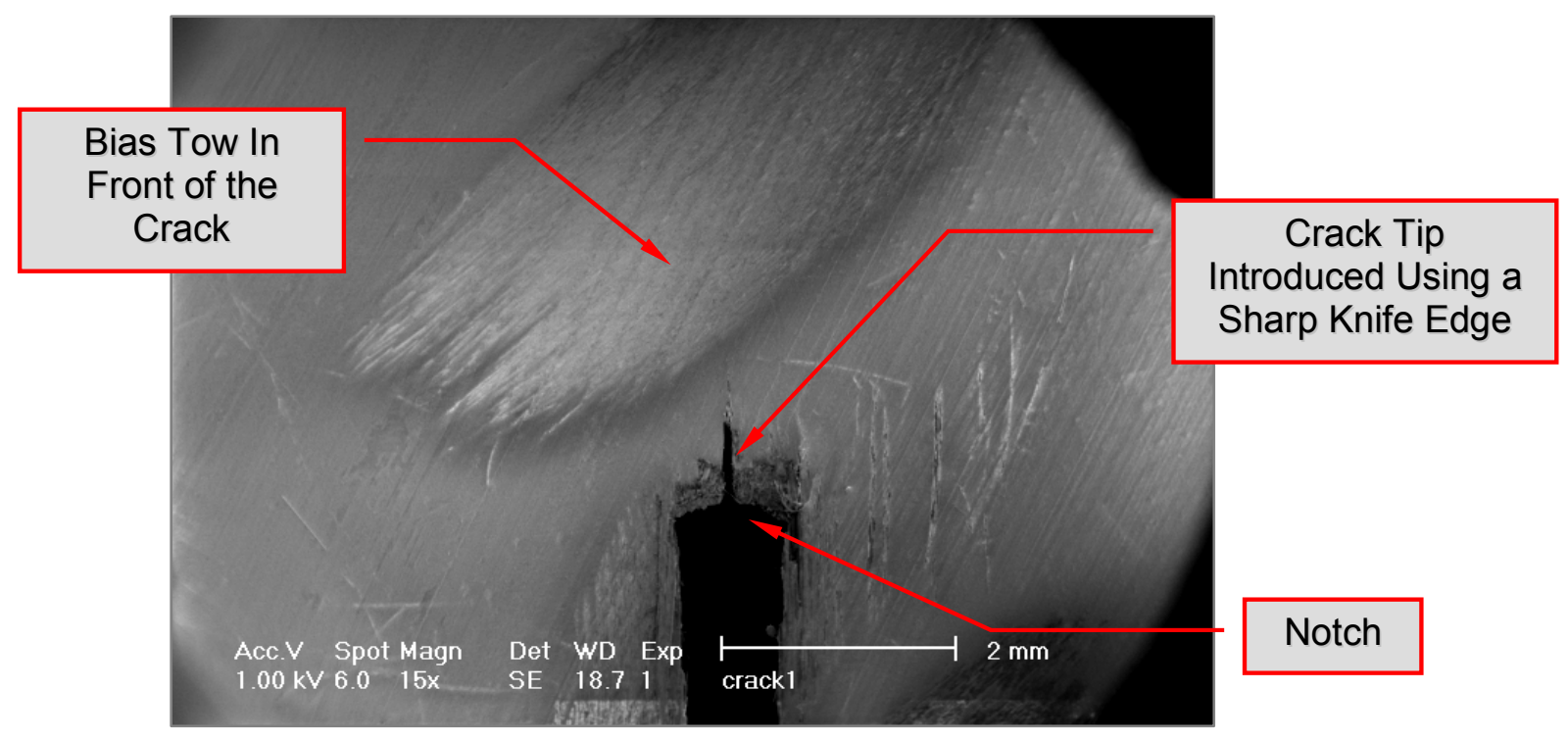

Figure 2 (b): Initial notch and crack tip in CTS 


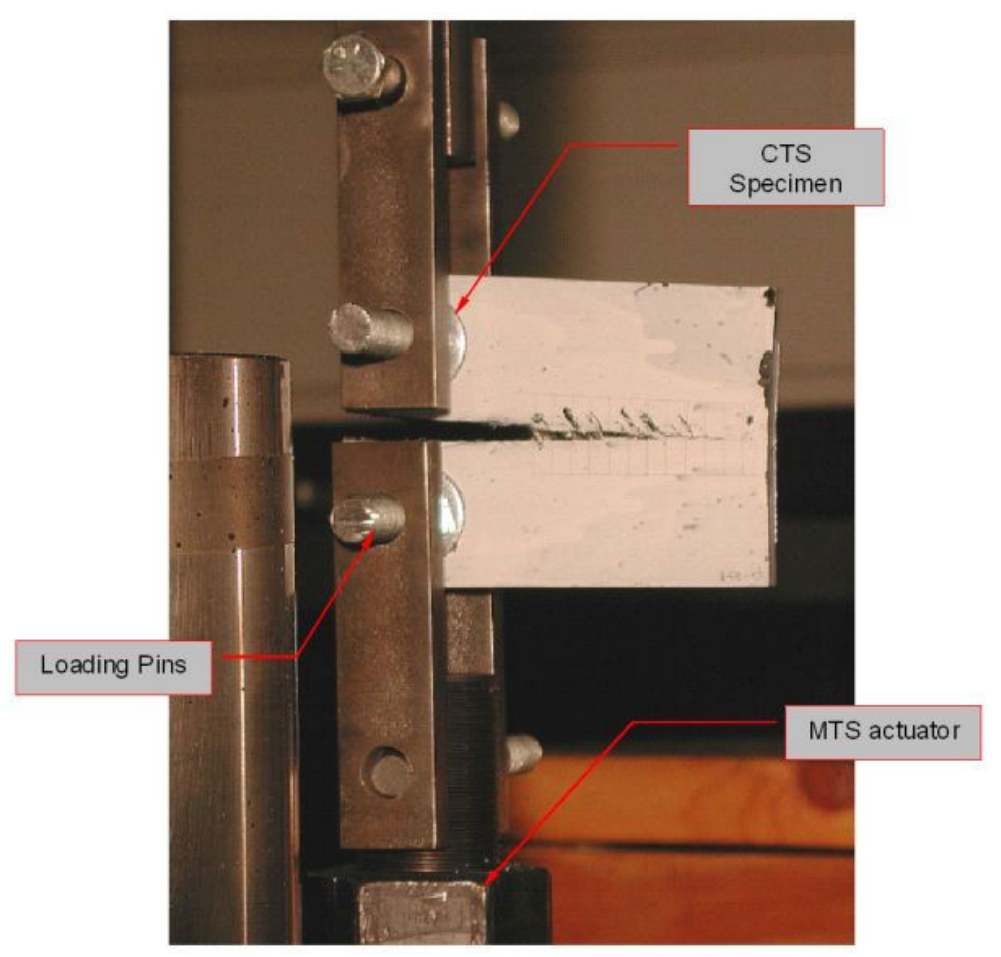

Figure 2 (c): CTS experimental set-up

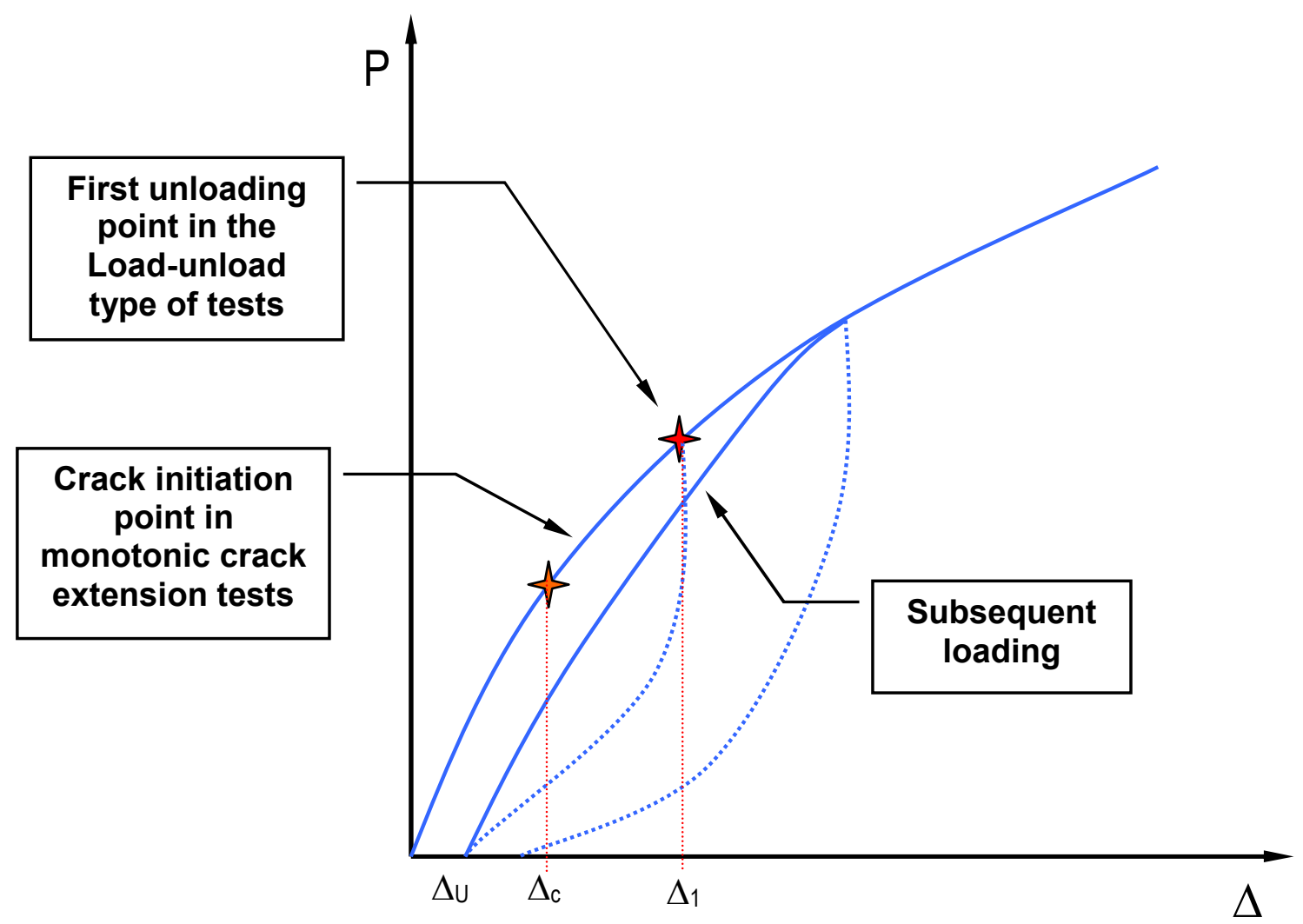

Figure 2 (d): Loading cycle in a typical cyclic fracture test 


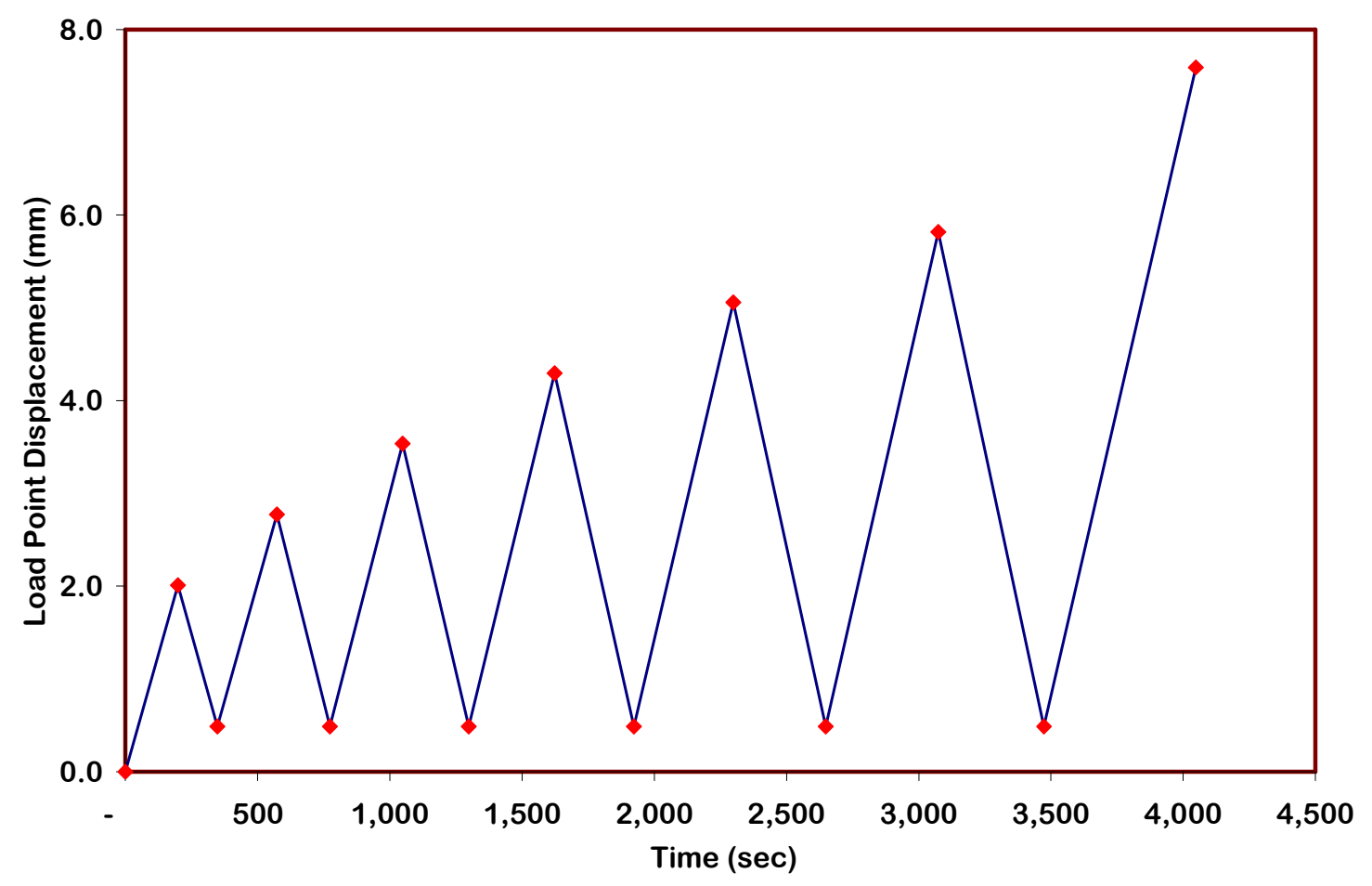

Figure 2 (e): Applied load point displacement as a function of time

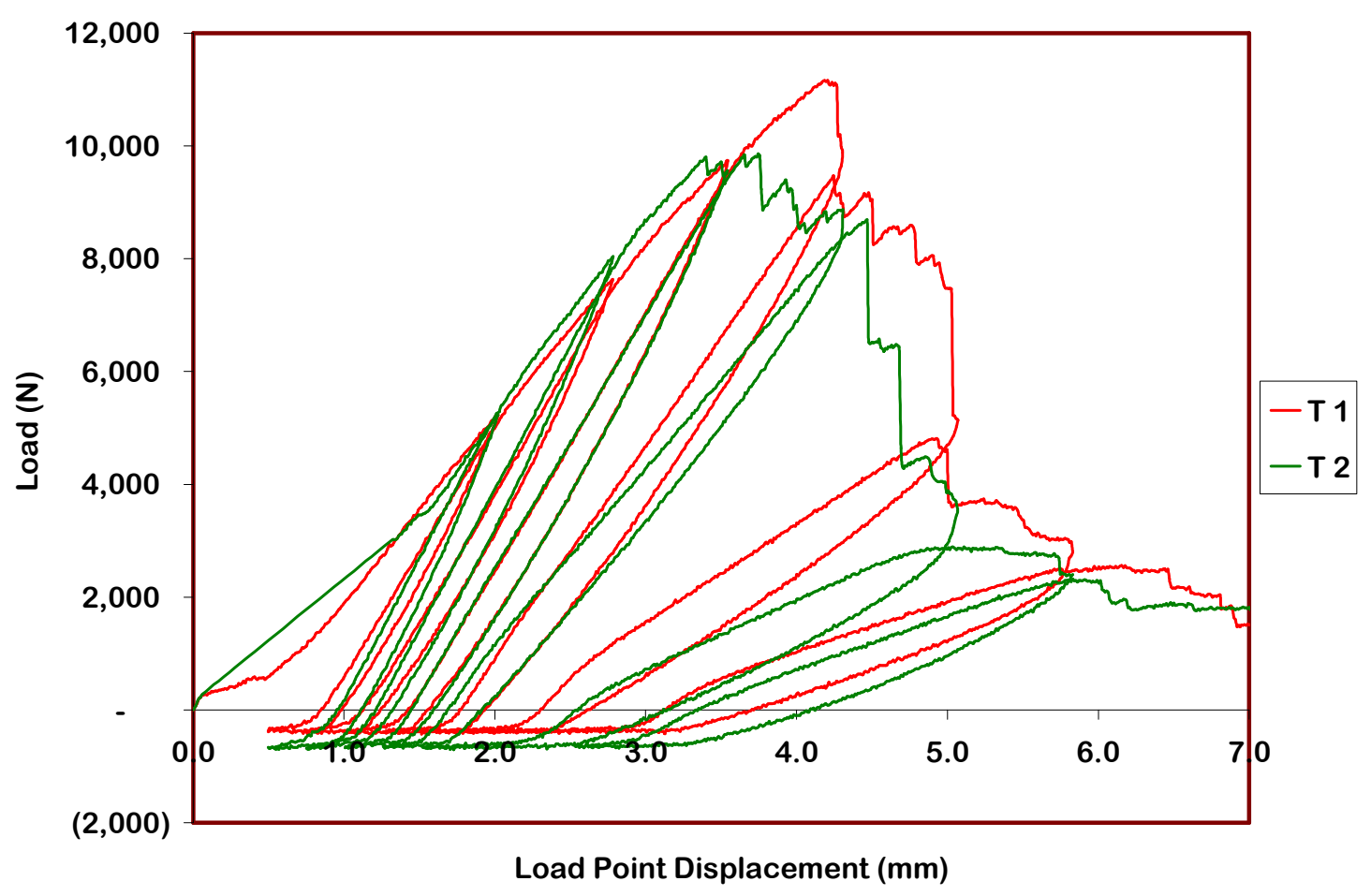

Figure 2 (f): P vs. $\Delta$ behavior for cyclic CTS fracture test (Hetron) 


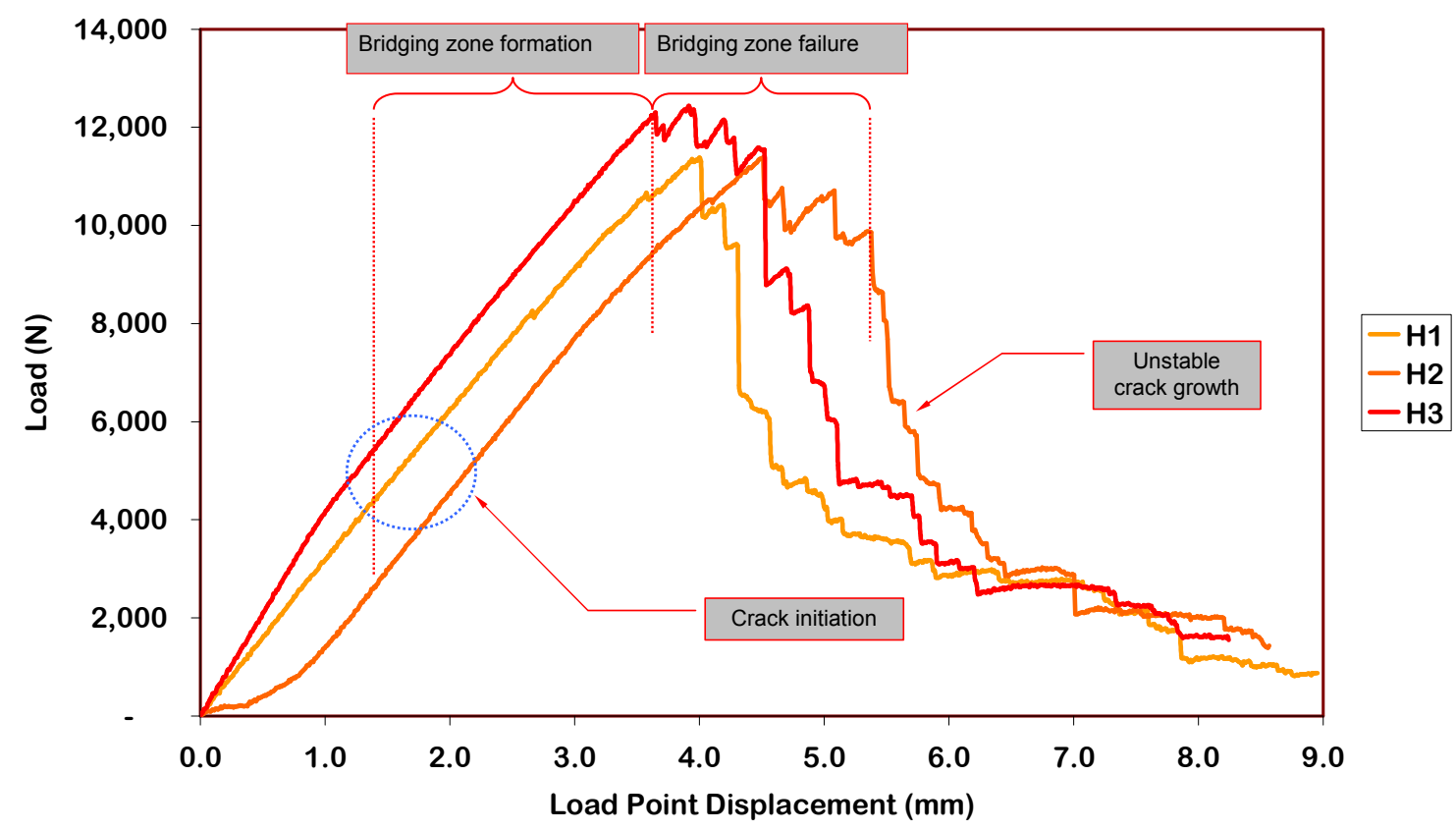

Figure 3 (a): P vs. $\Delta$ behavior for monotonic CTS fracture tests on Hetron specimens

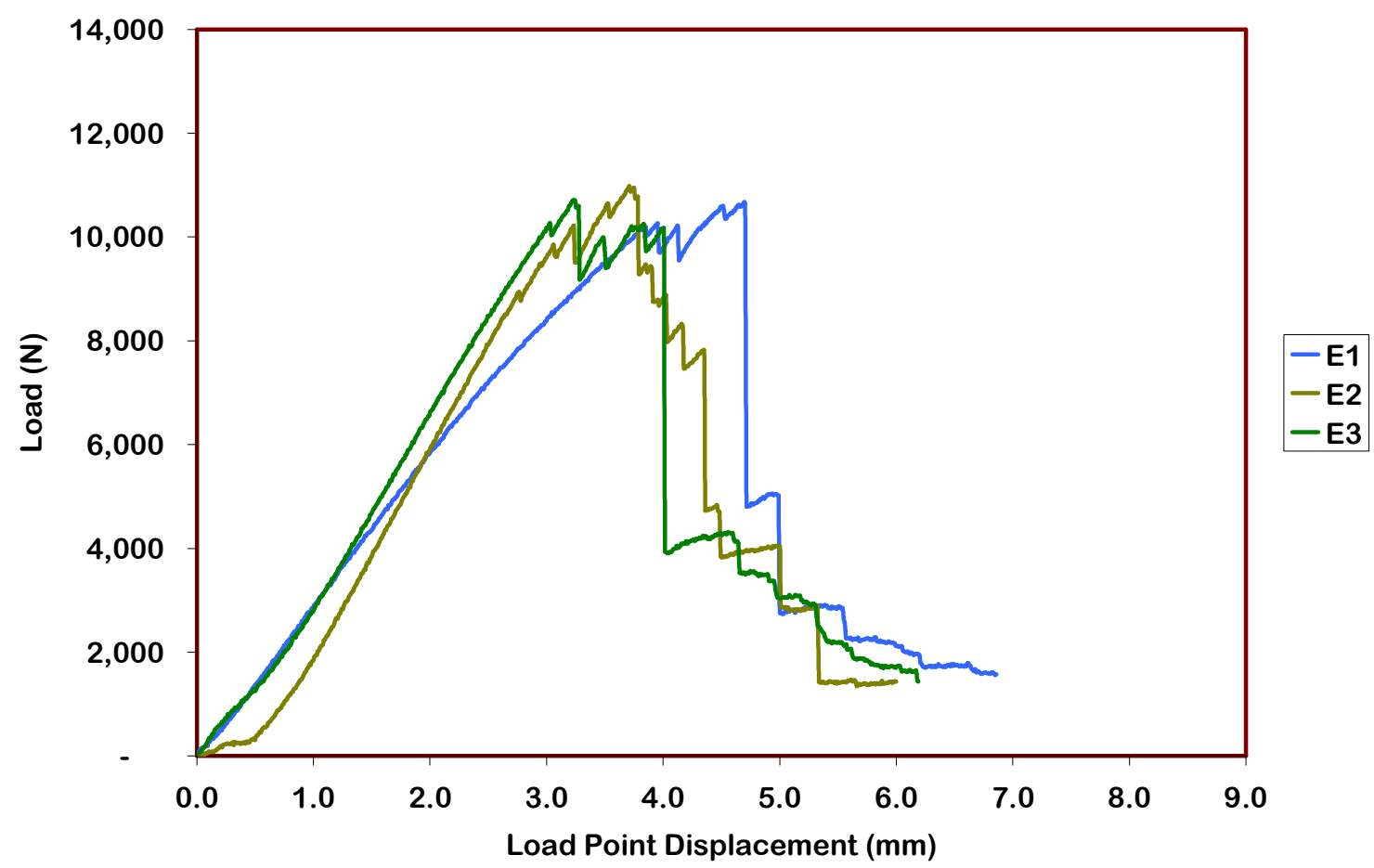

Figure 3 (b): P vs. $\Delta$ behavior for monotonic CTS fracture tests on Epon specimens 


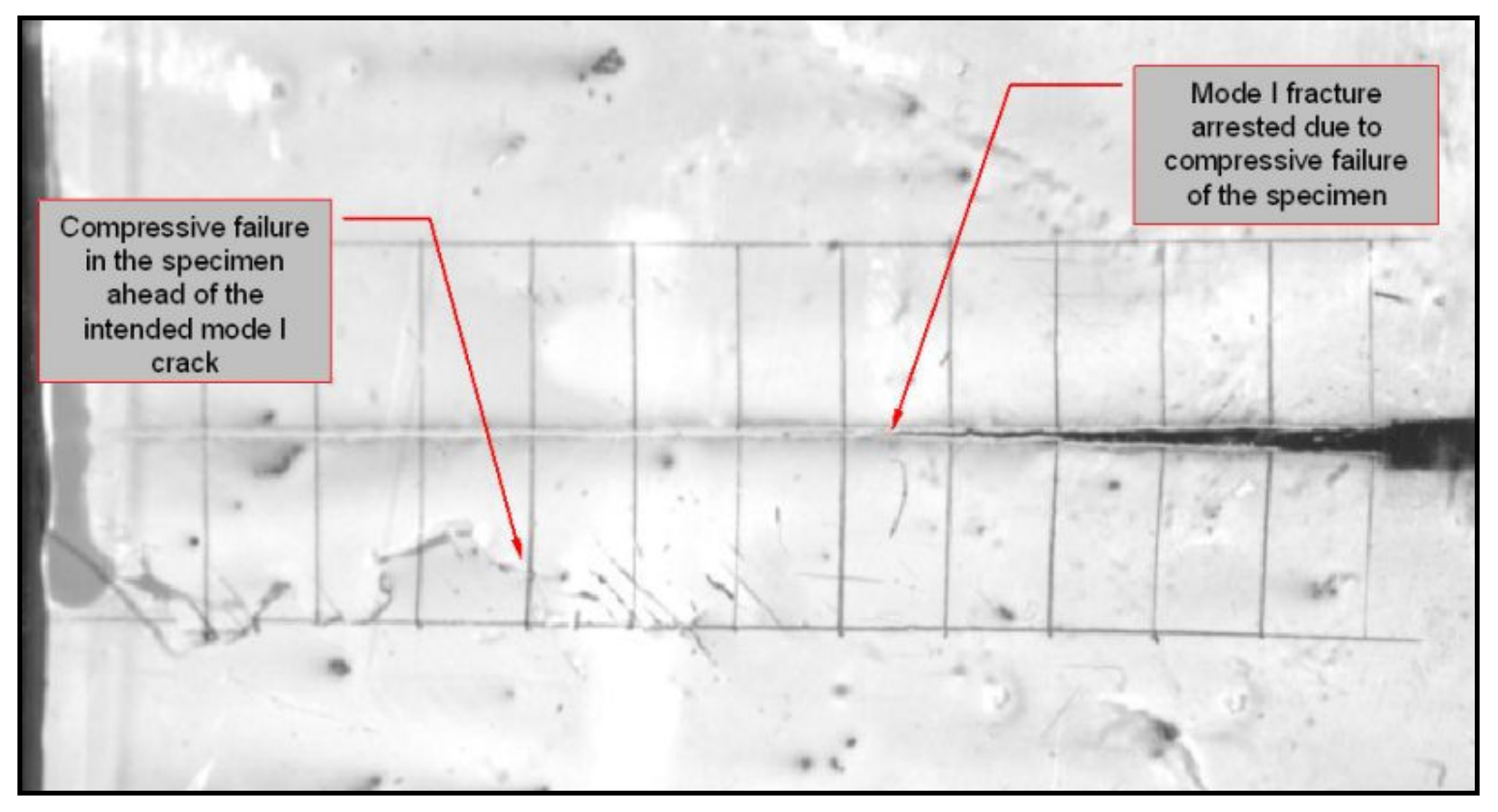

Figure 3 (c): Bridging zone formation and failure

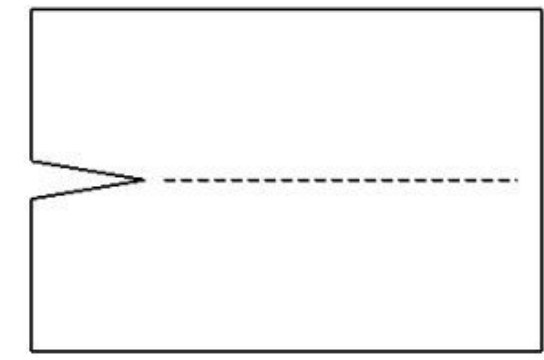

a. Initial notch position with intended crack path

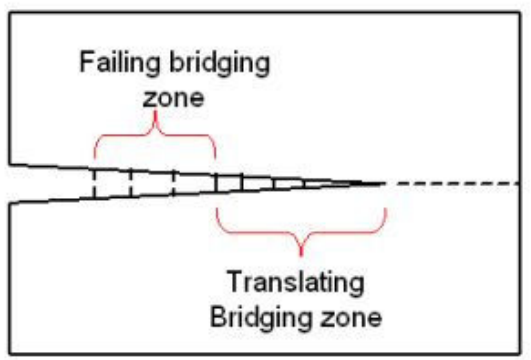

c. Bridging zone of constant length travels with further crack opening at plateau load

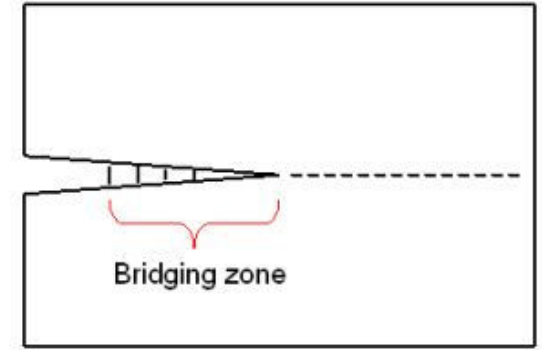

b. Crack opening with bridging zone formation

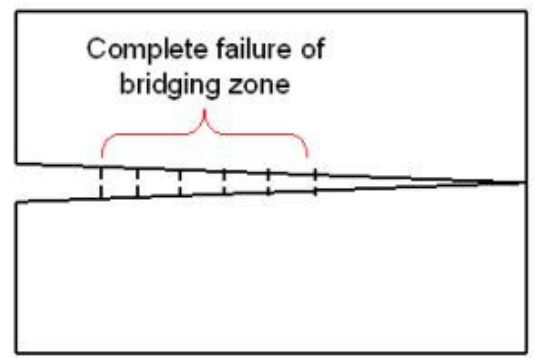

d. Failure of bridging zone leading to sudden drop in the loads

Figure 3 (d): Formation and translation of bridging zone 


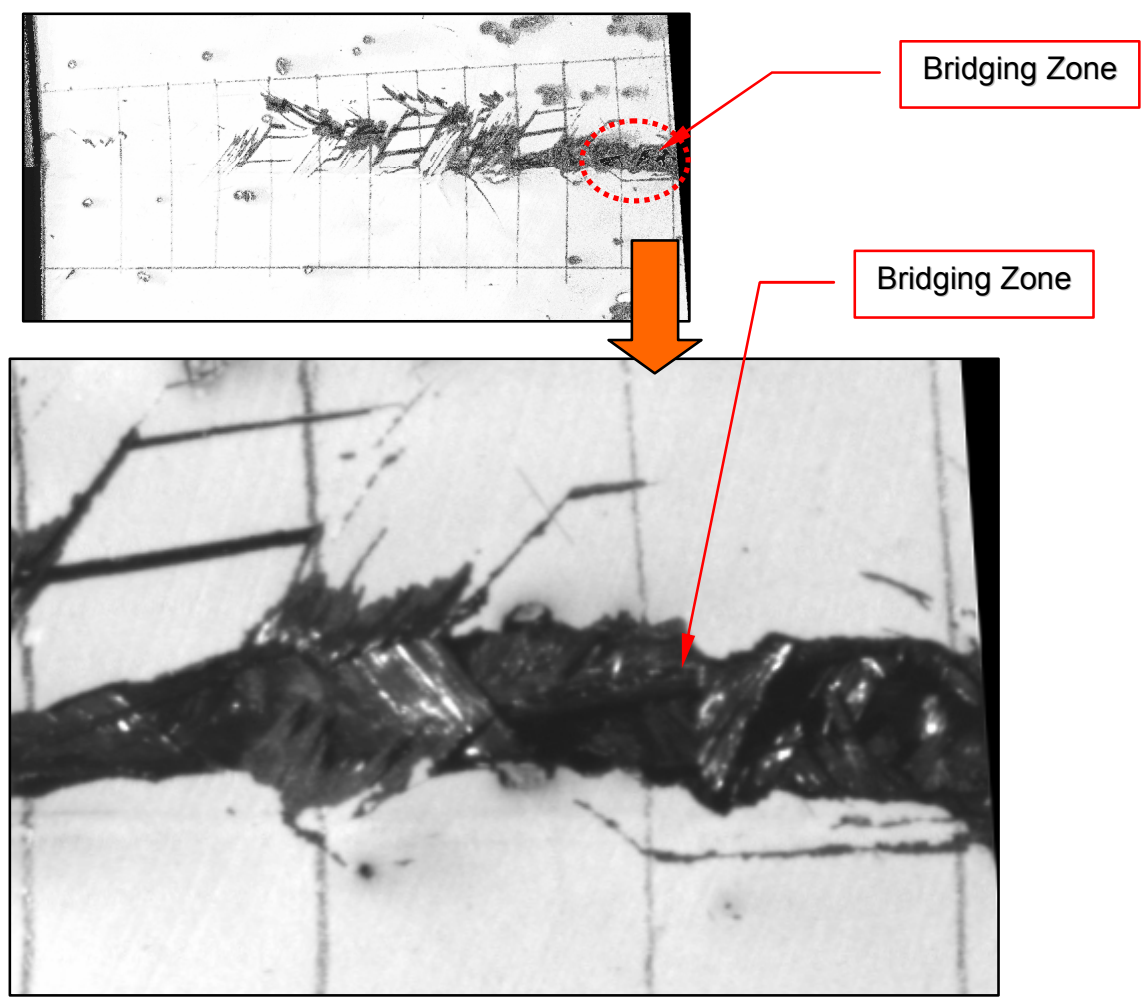

Figure 3 (e): Crack opening and formation of bridging zone

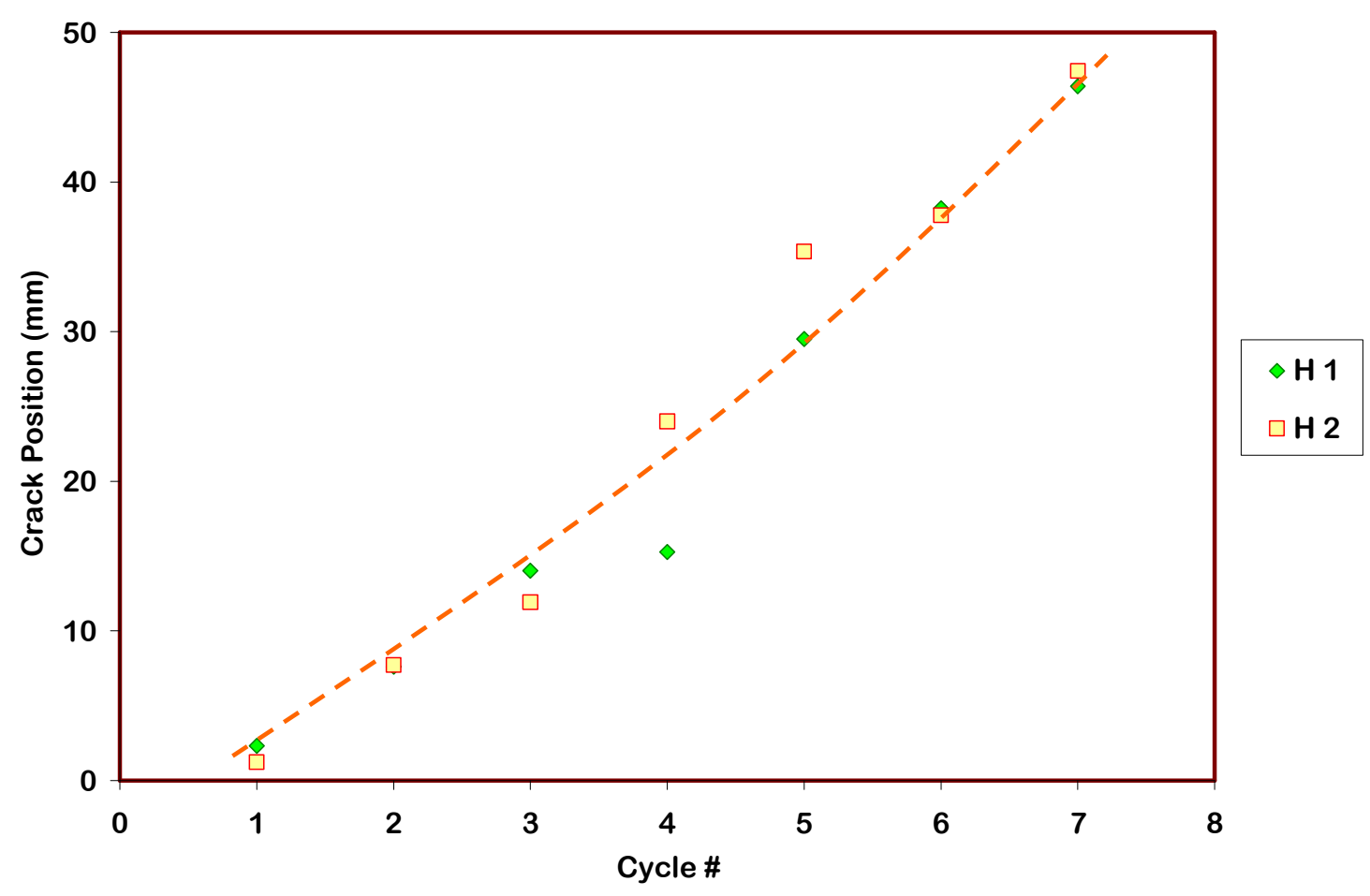

Figure 4 (a): Crack extension vs. time for Hetron specimens 


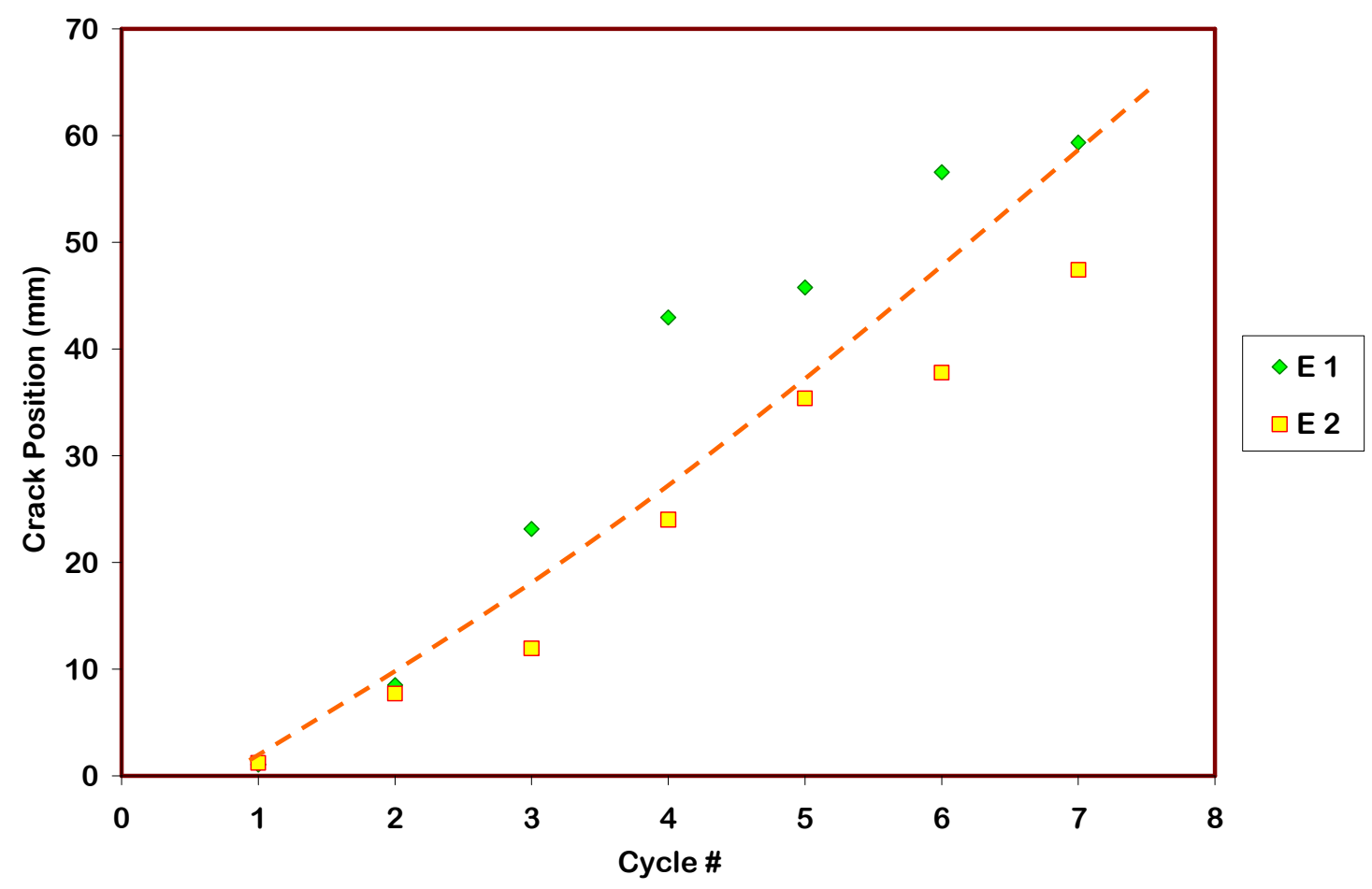

Figure 4 (b): Crack extension vs. time for Epon specimens

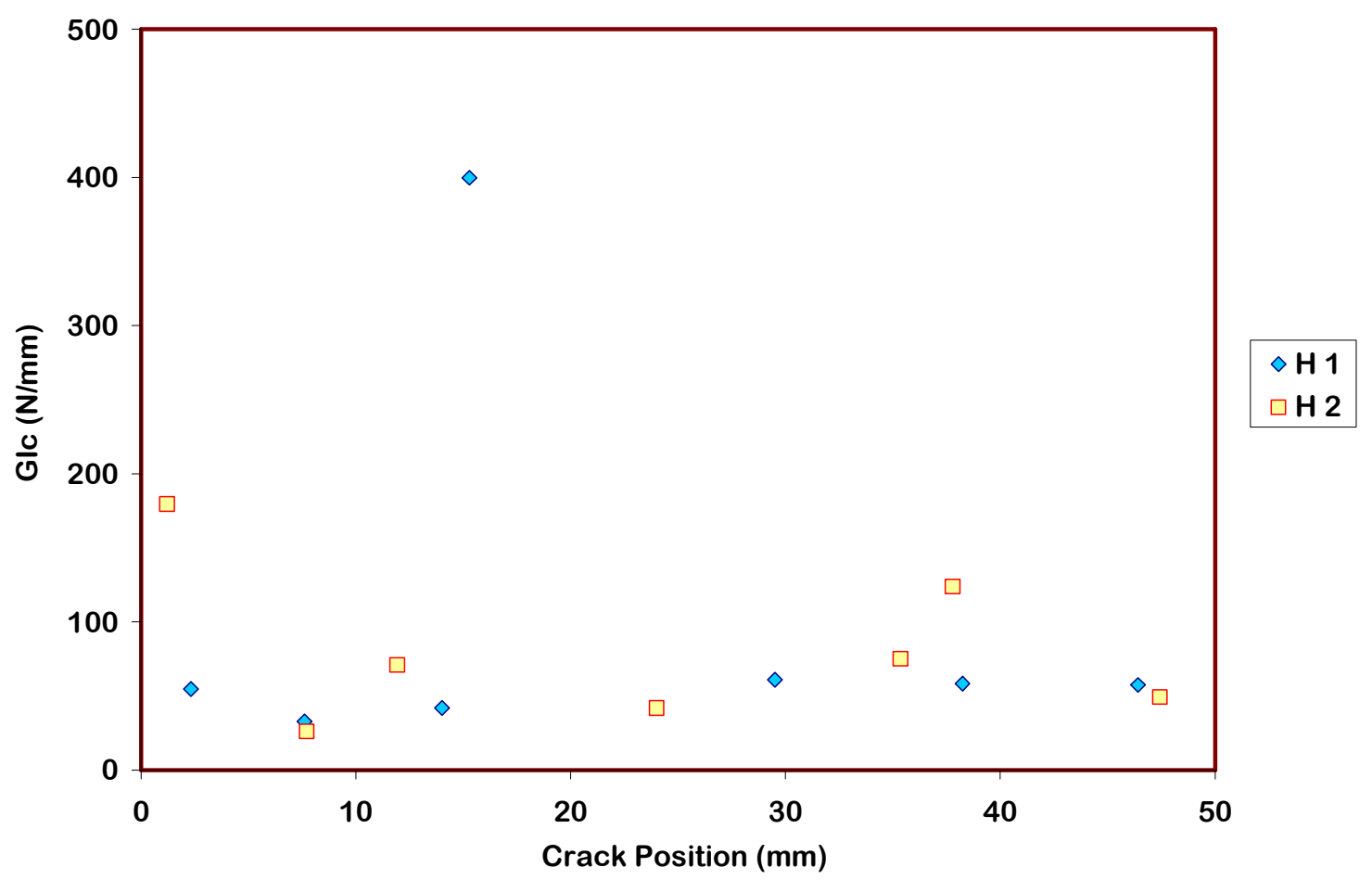

Figure 4 (c): Fracture energy as a function of crack extension for Hetron 


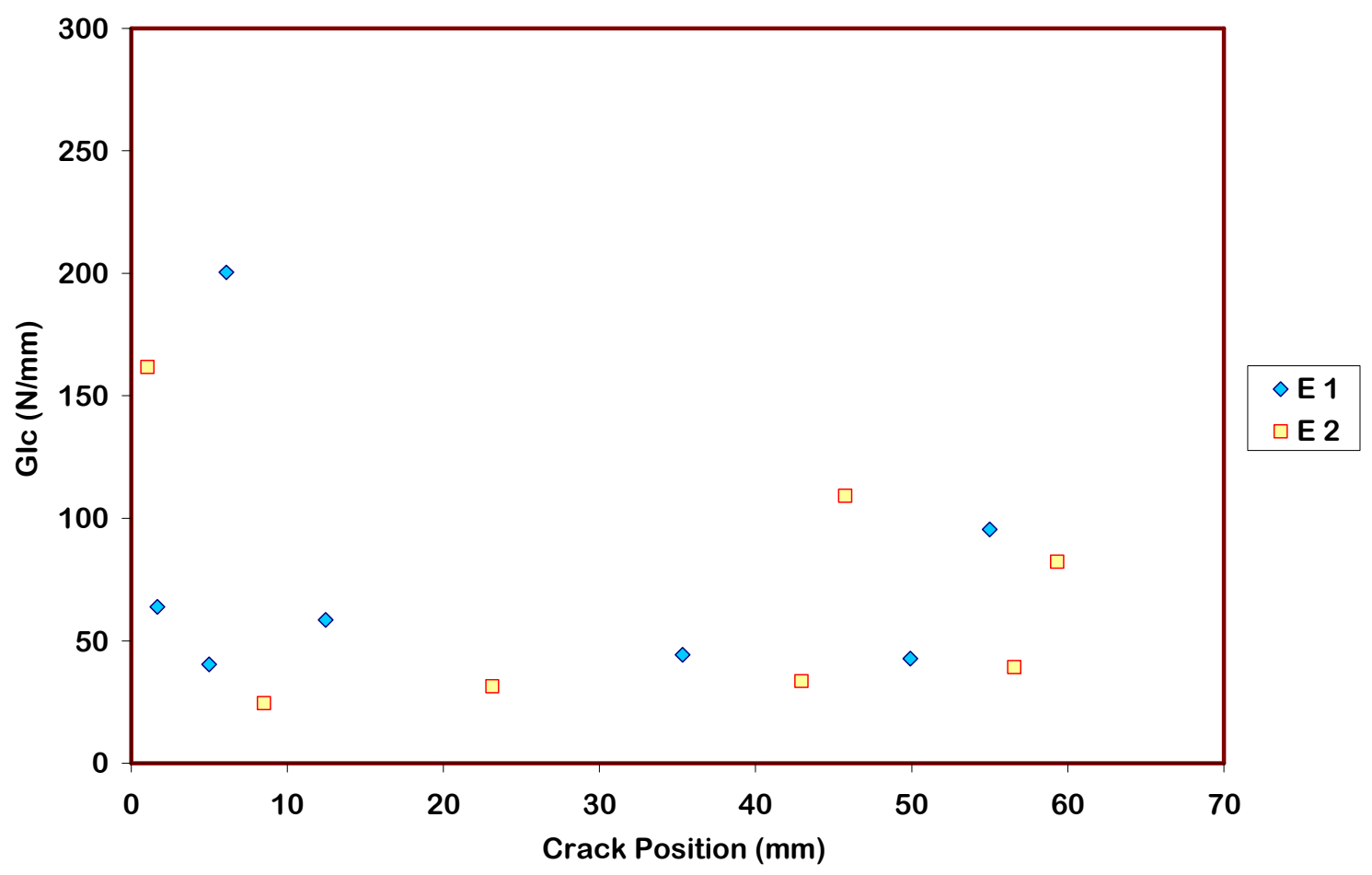

Figure 4 (d): Fracture energy as a function of crack extension for Epon

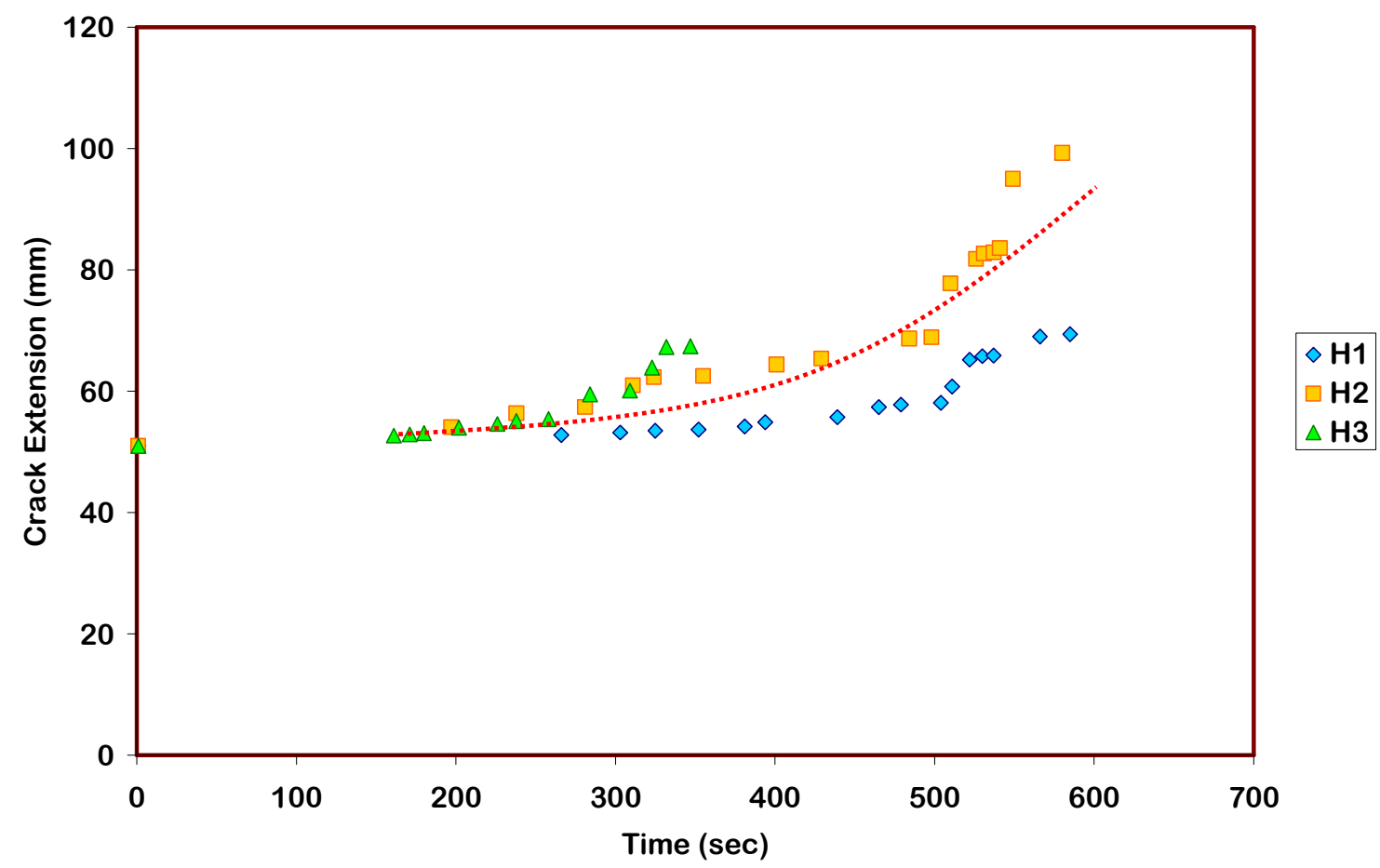

Figure 4 (e): Crack extension vs. time for monotonic fracture tests on Hetron 


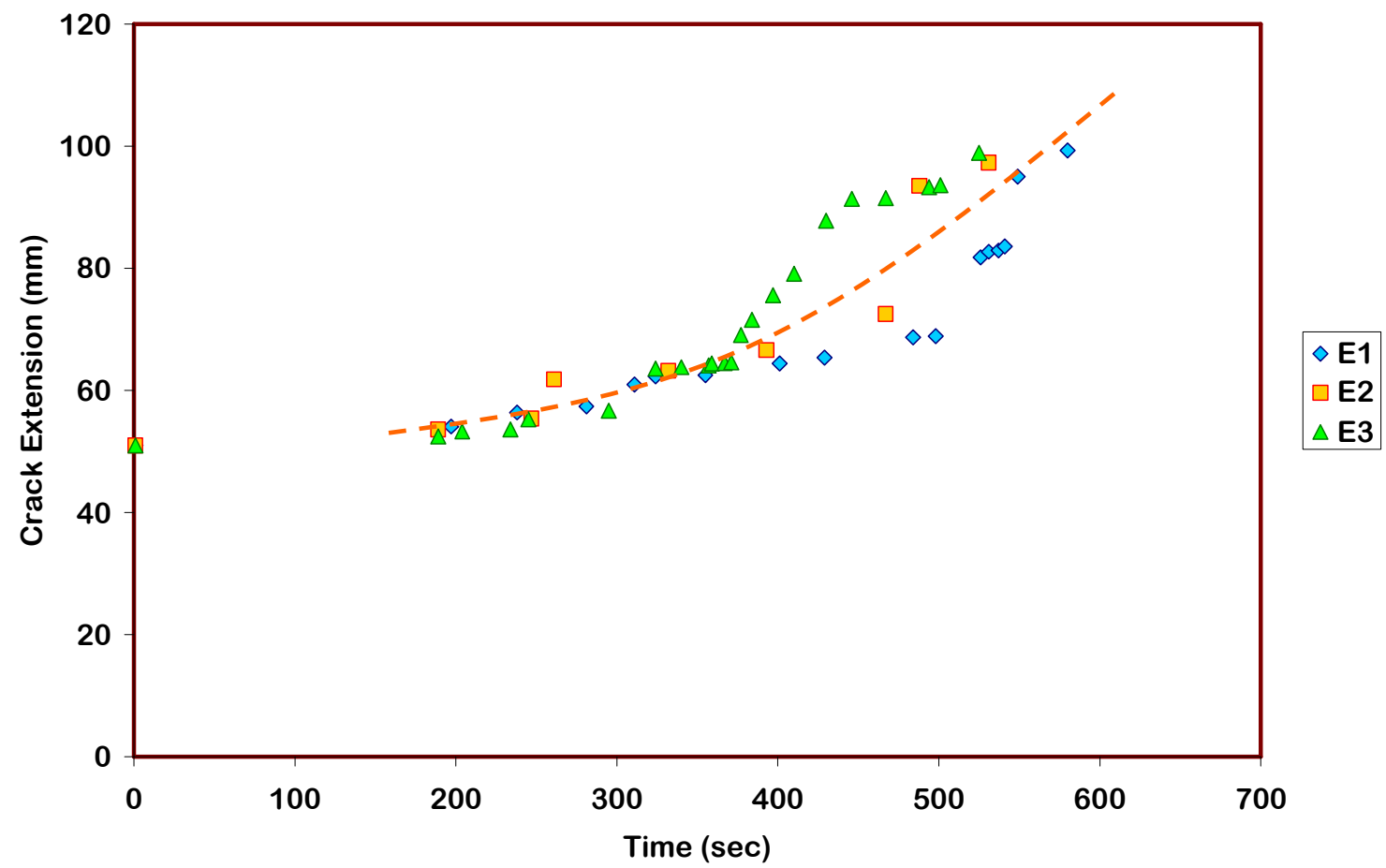

Figure 4 (f): Crack extension vs. time for monotonic fracture tests on Epon

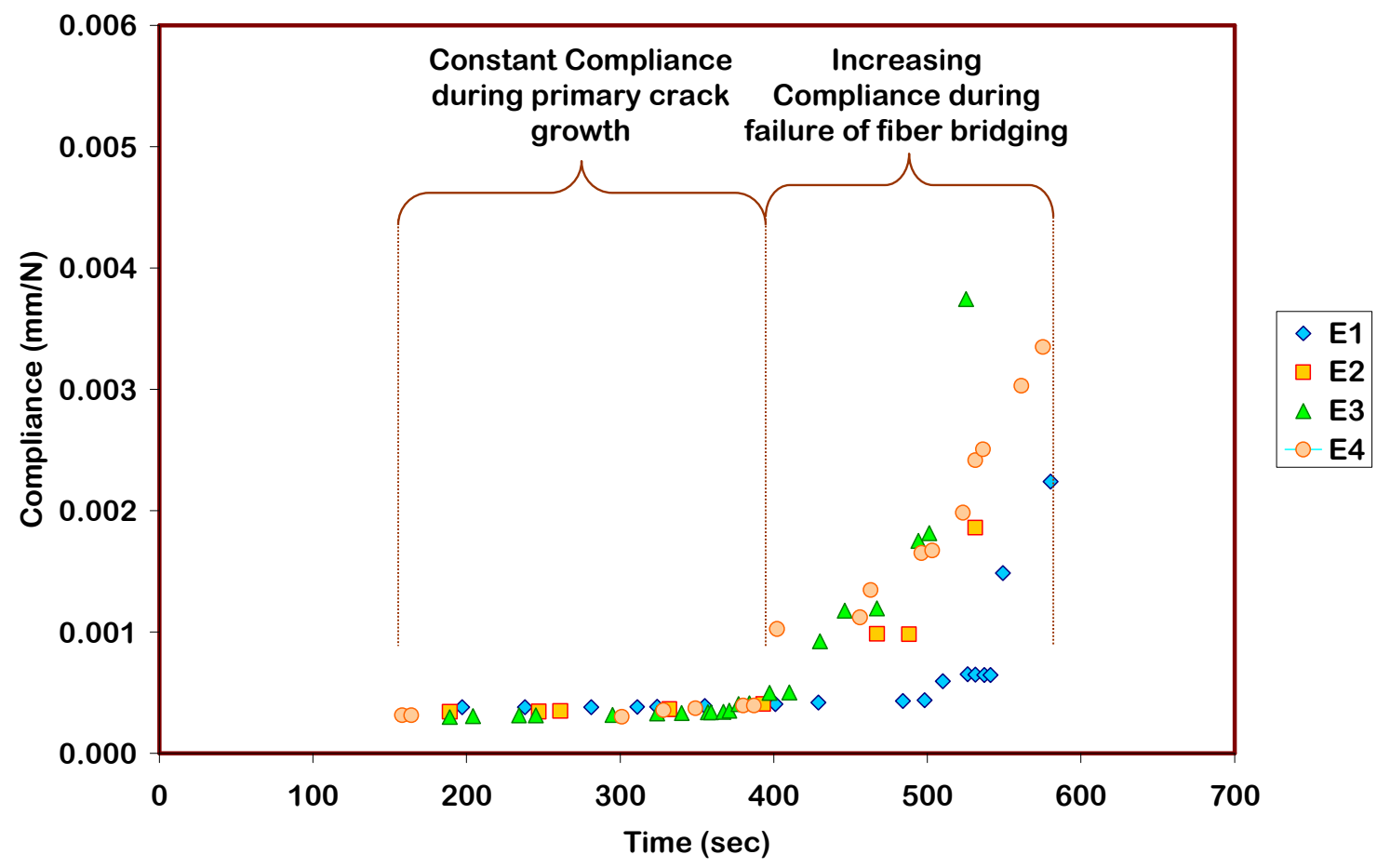

Figure $4(\mathrm{~g})$ : Compliance vs. time for Hetron specimens 


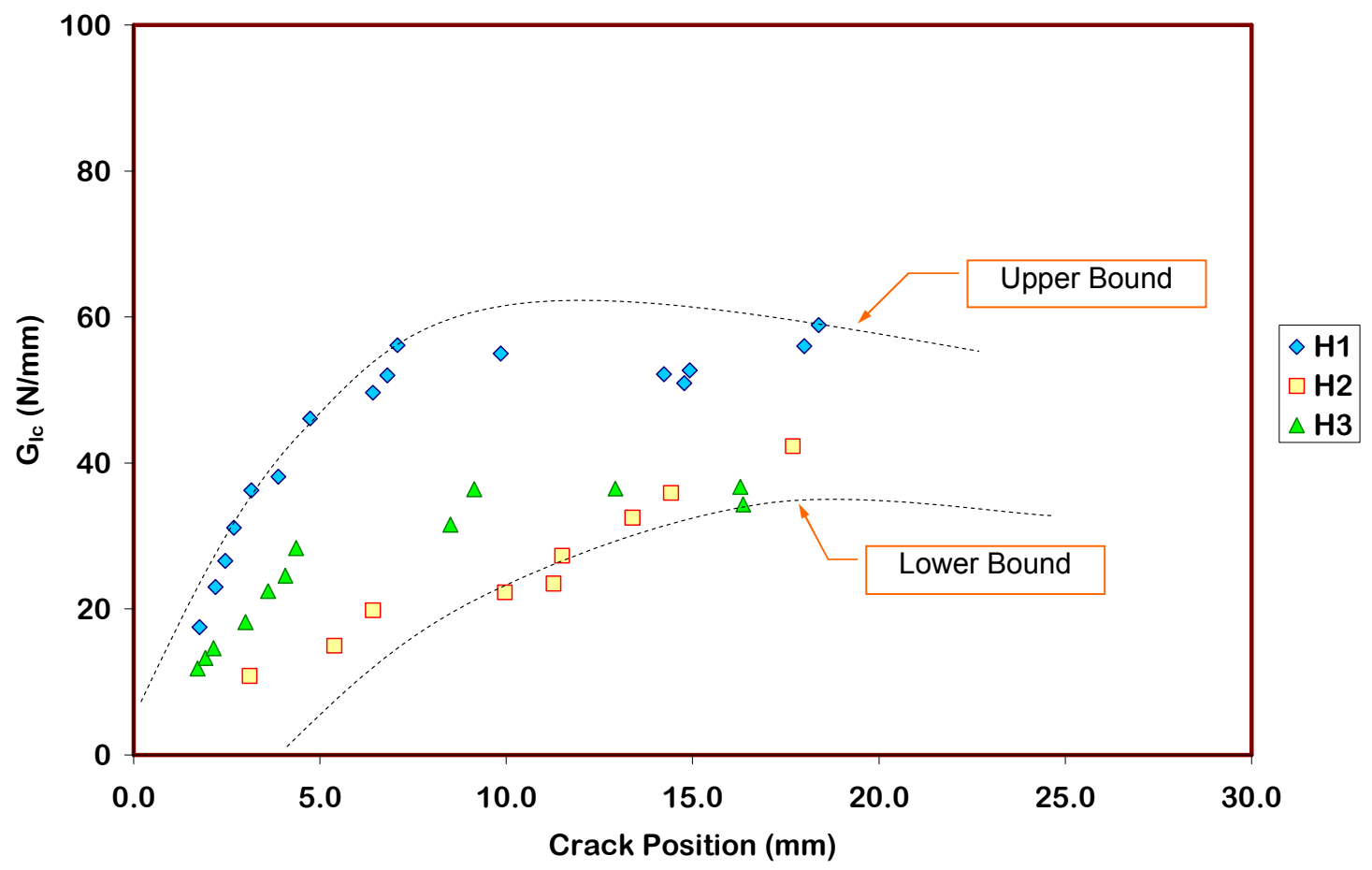

Figure 4 (h): Fracture energy vs. crack extension for monotonic fracture of Hetron

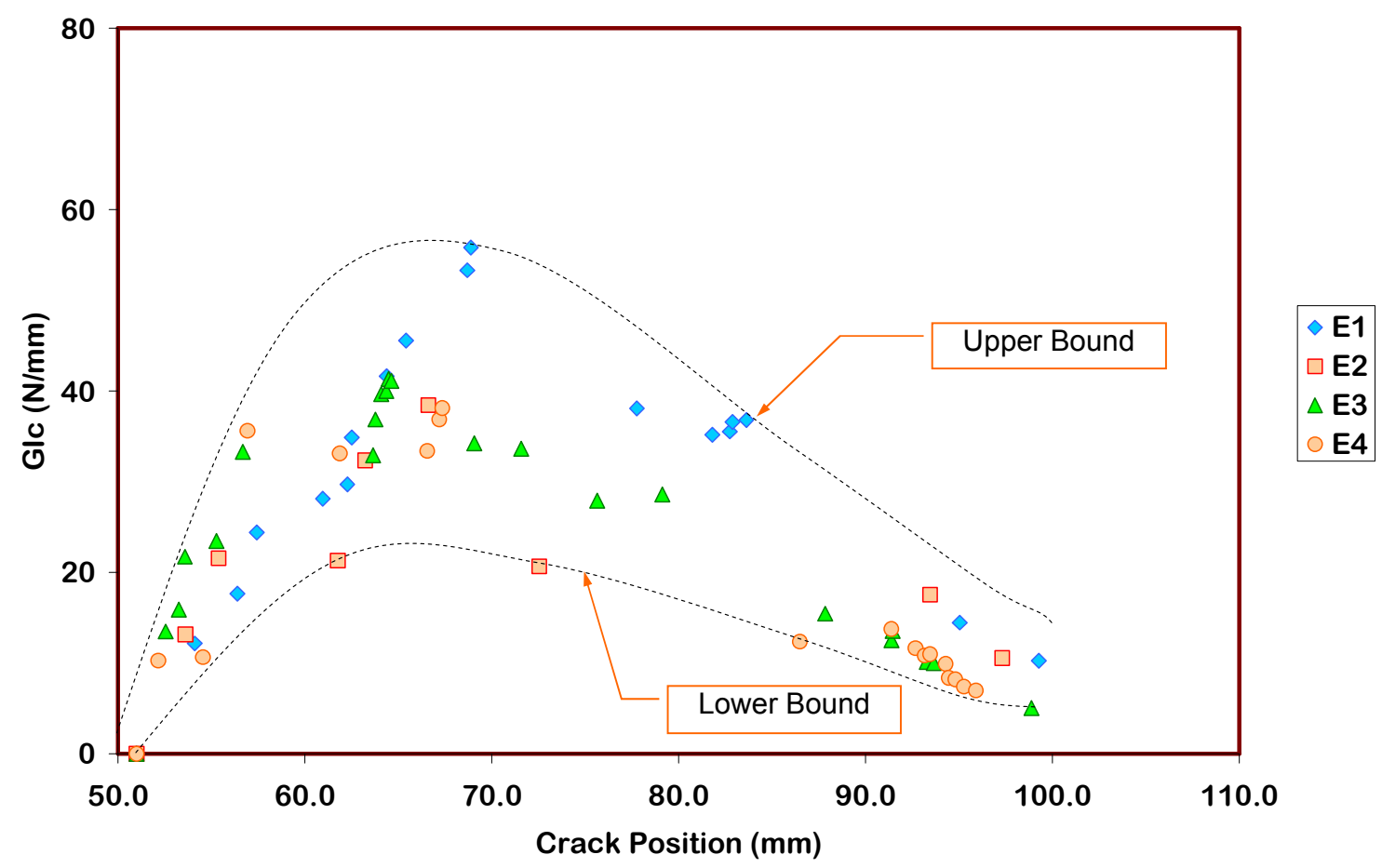

Figure 4 (i): Fracture energy vs. crack extension for monotonic fracture of Epon 


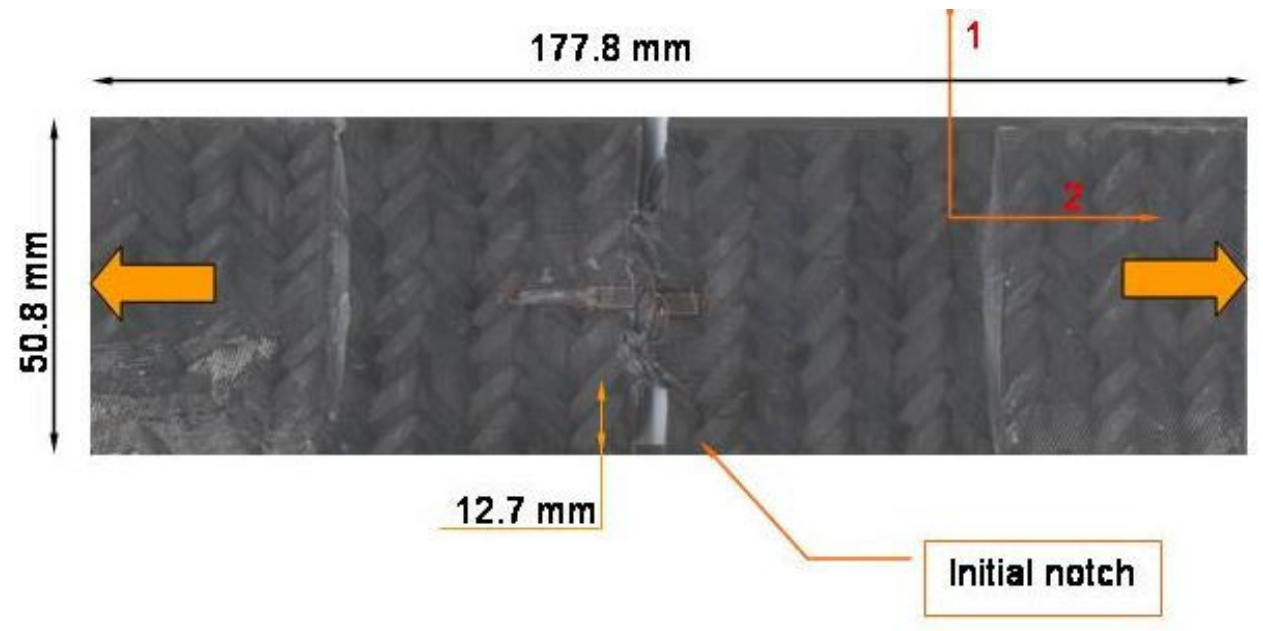

Figure 5: Notched tension specimen to investigate the transverse fiber tow strength
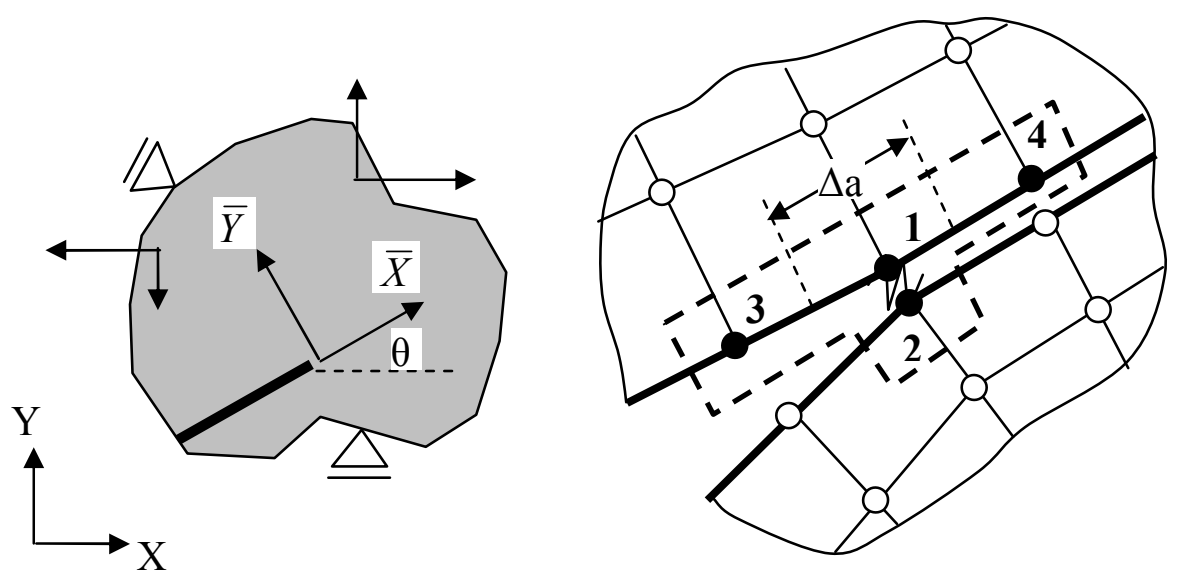

Figure 6 (a): Interface element for slant crack lying in $(\mathrm{X}, \mathrm{Y})$ plane 


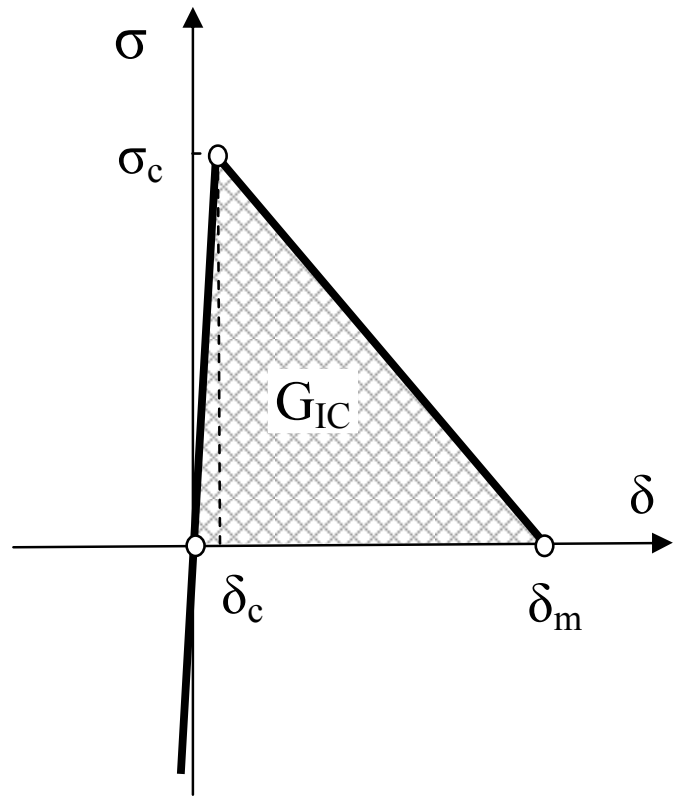

Figure 6 (b): Triangle type cohesive law used in DCZM

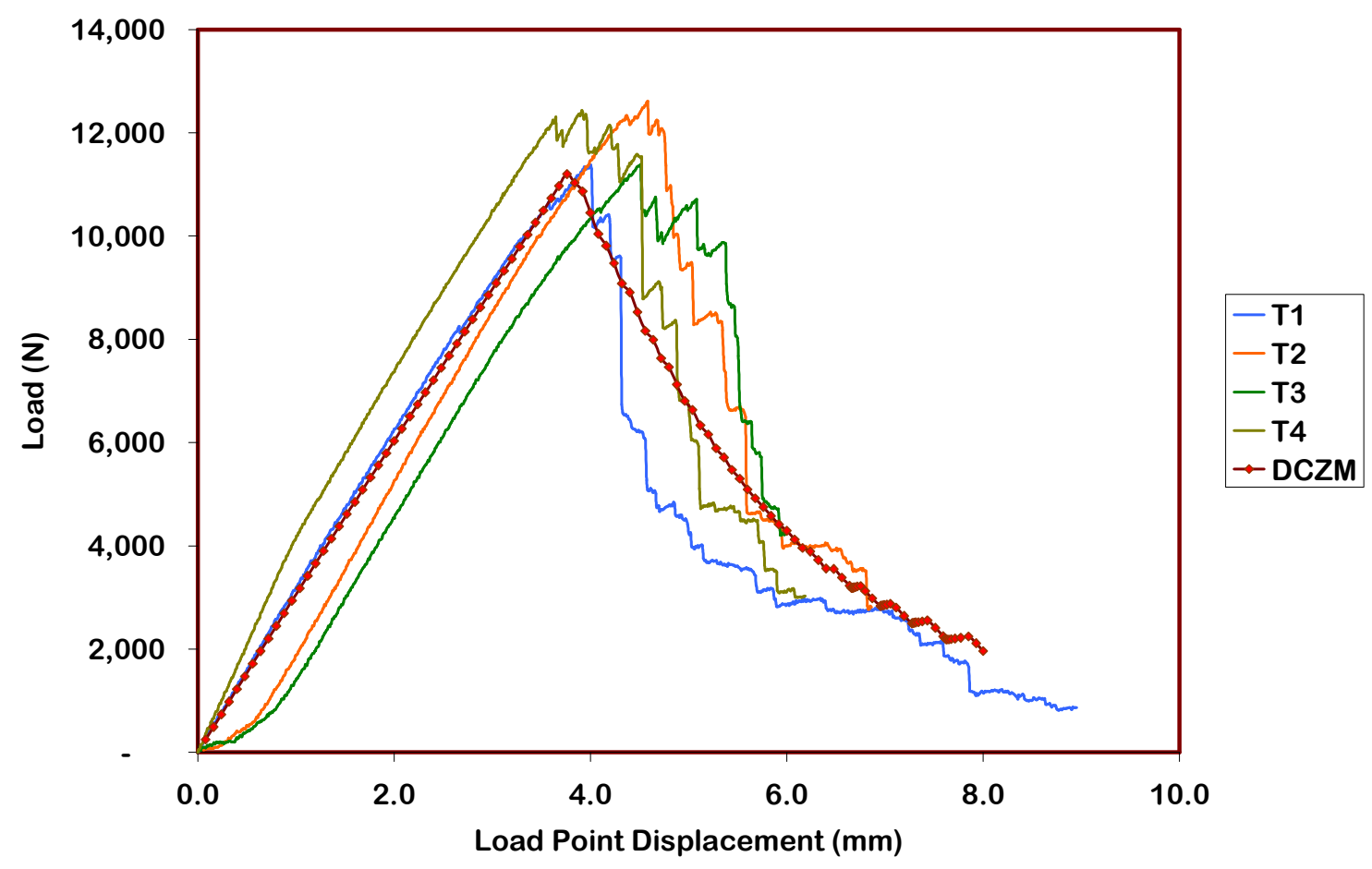

Figure 6 (c): DCZM prediction for Hetron CTS specimens 


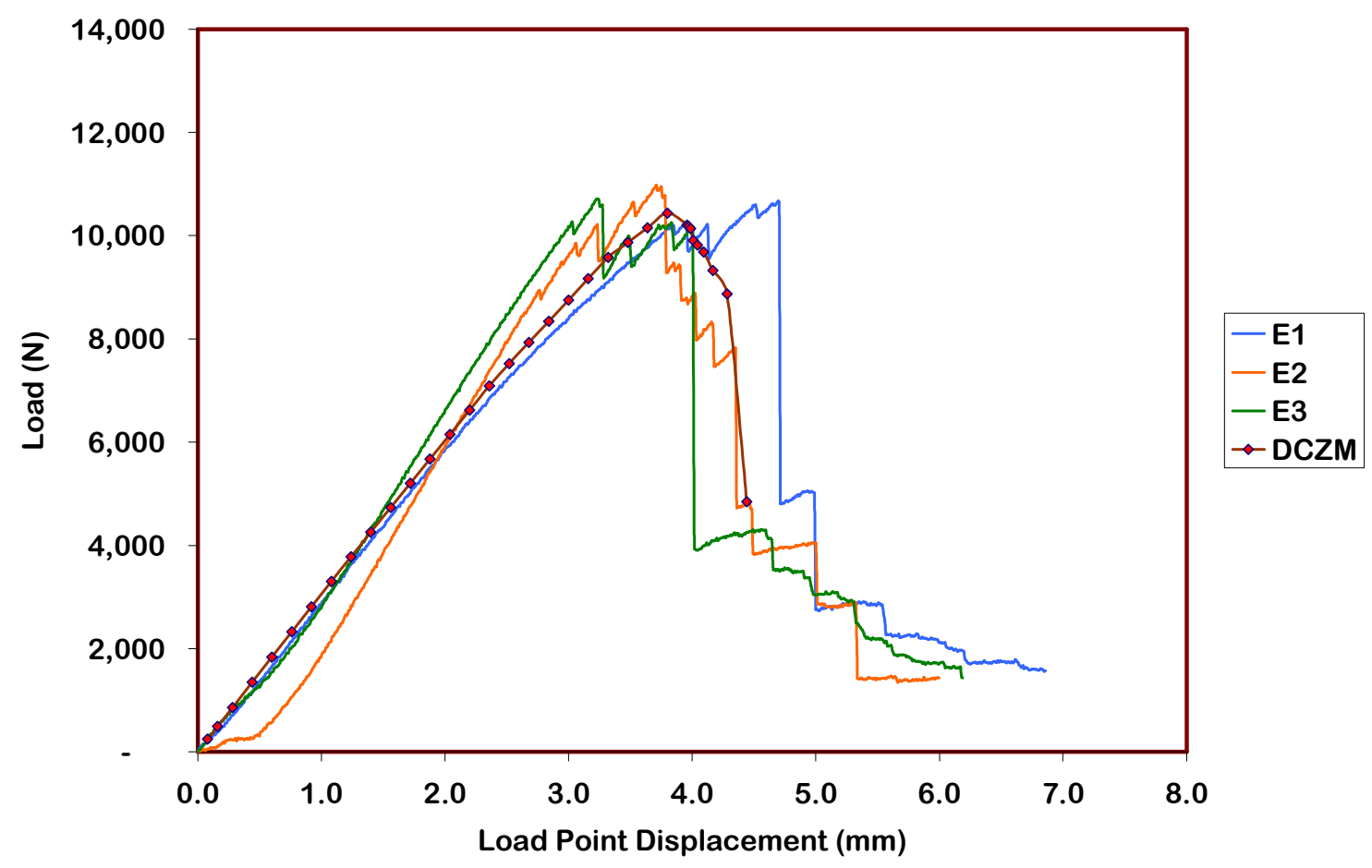

Figure 6 (d): DCZM prediction for Epon CTS specimens

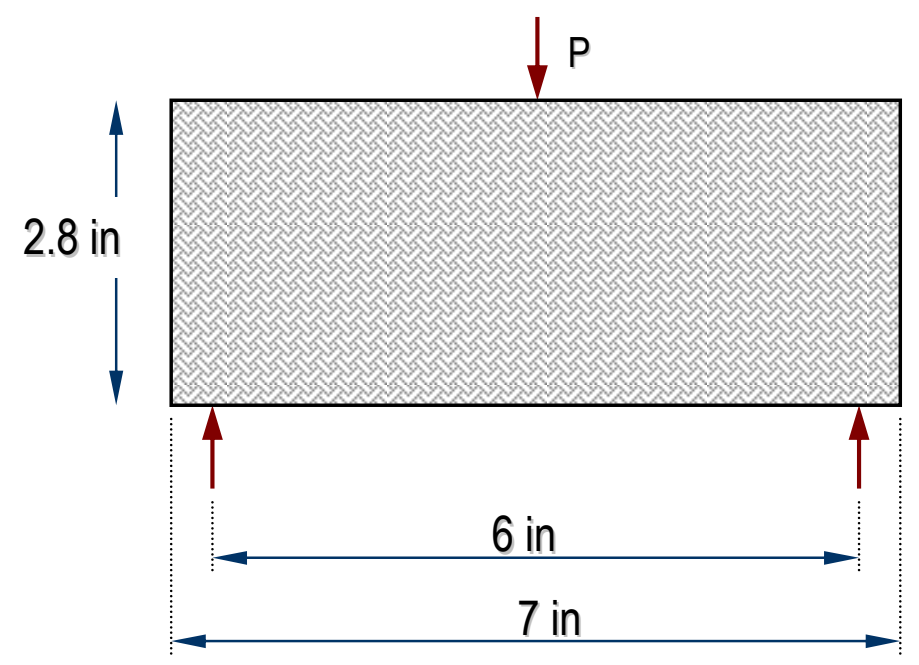

\section{Specification of the notch}

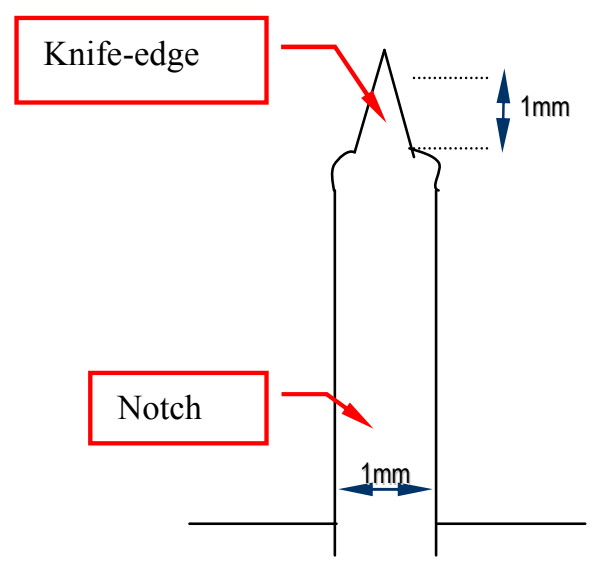

Fig 7 (a): Dimensions of the SENB test specimen and loading configuration 


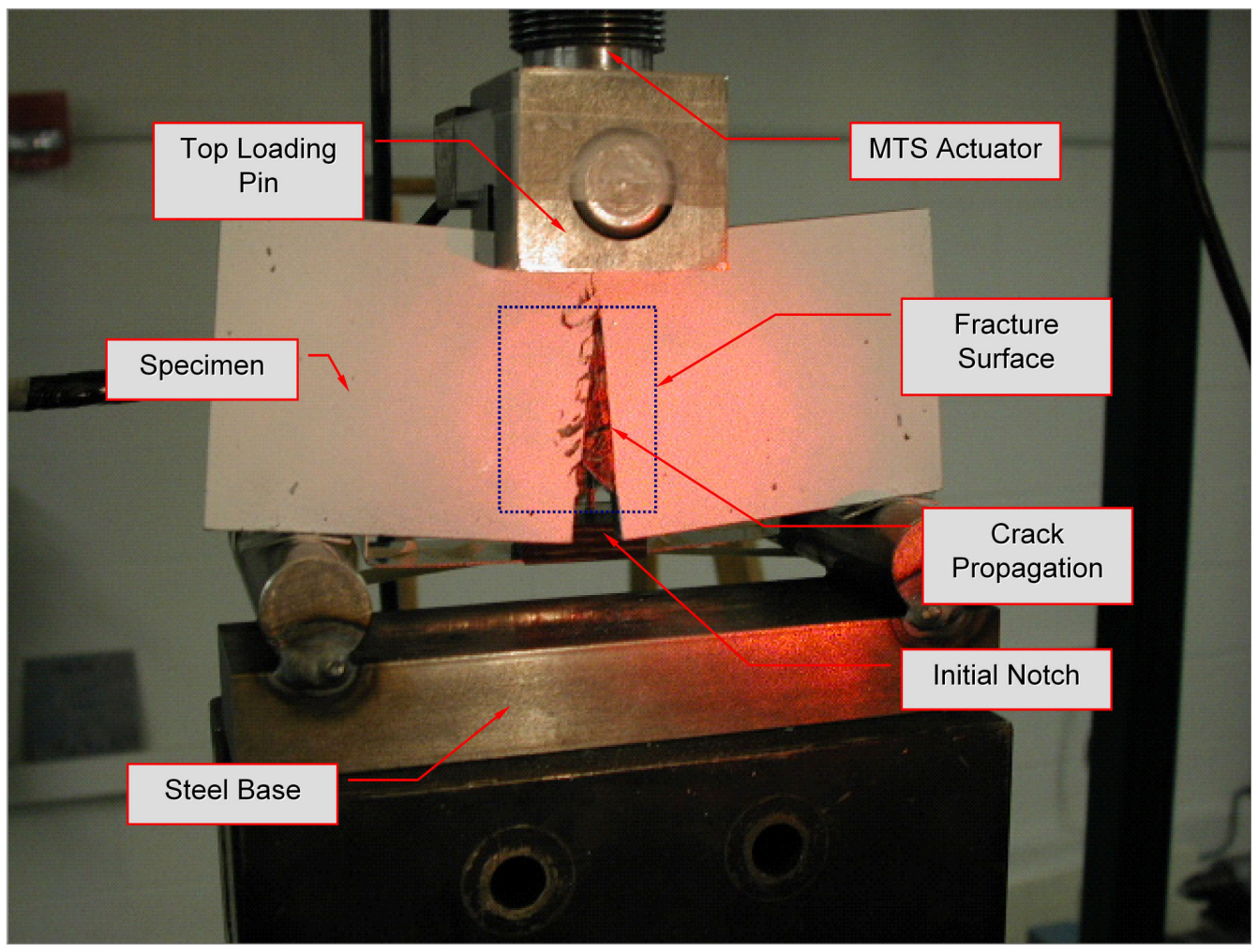

Fig. 7 (b): SENB fracture test fixture

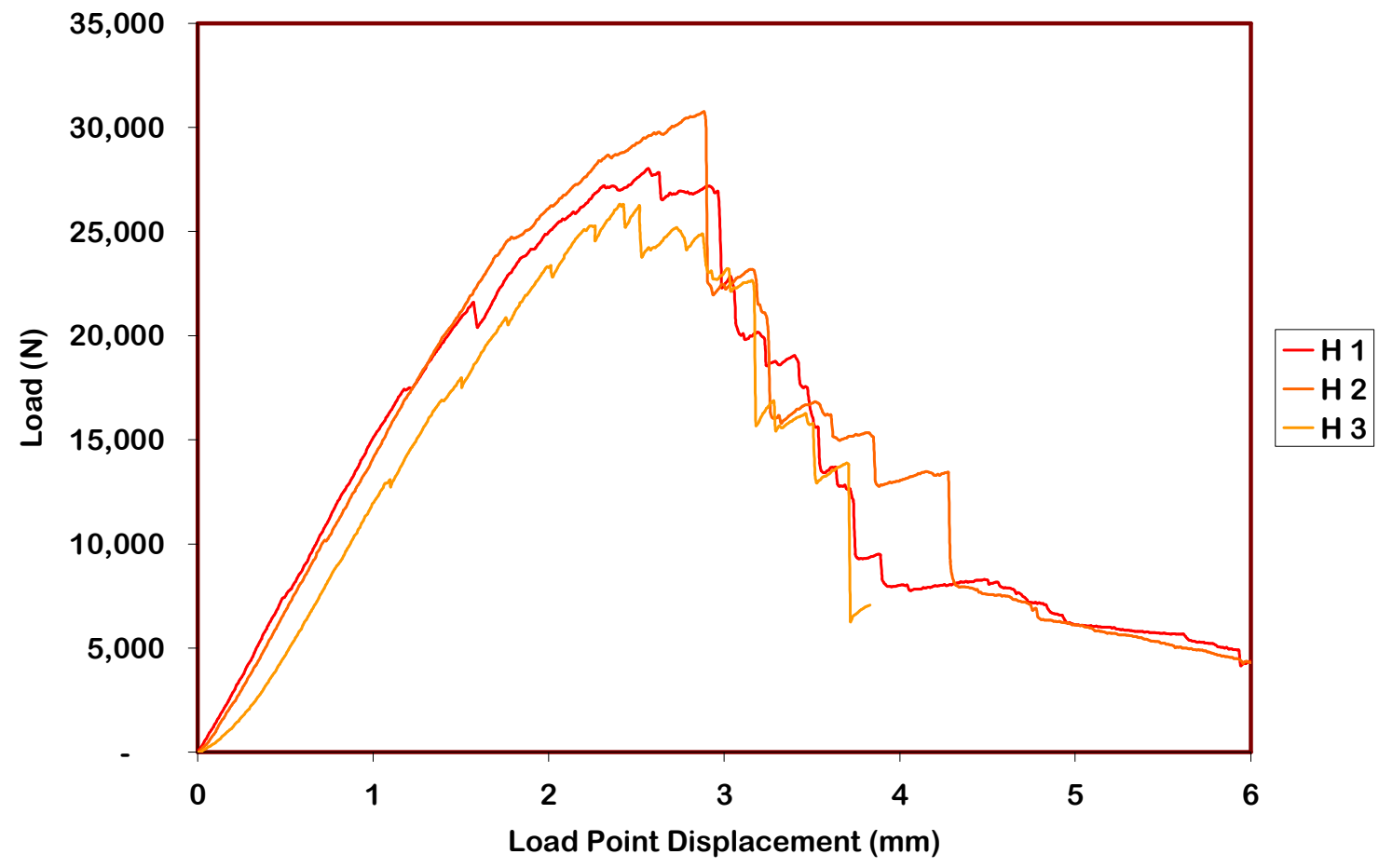

Fig. 7 (c): SENB monotonic fracture test P- $\Delta$ behavior for Hetron 


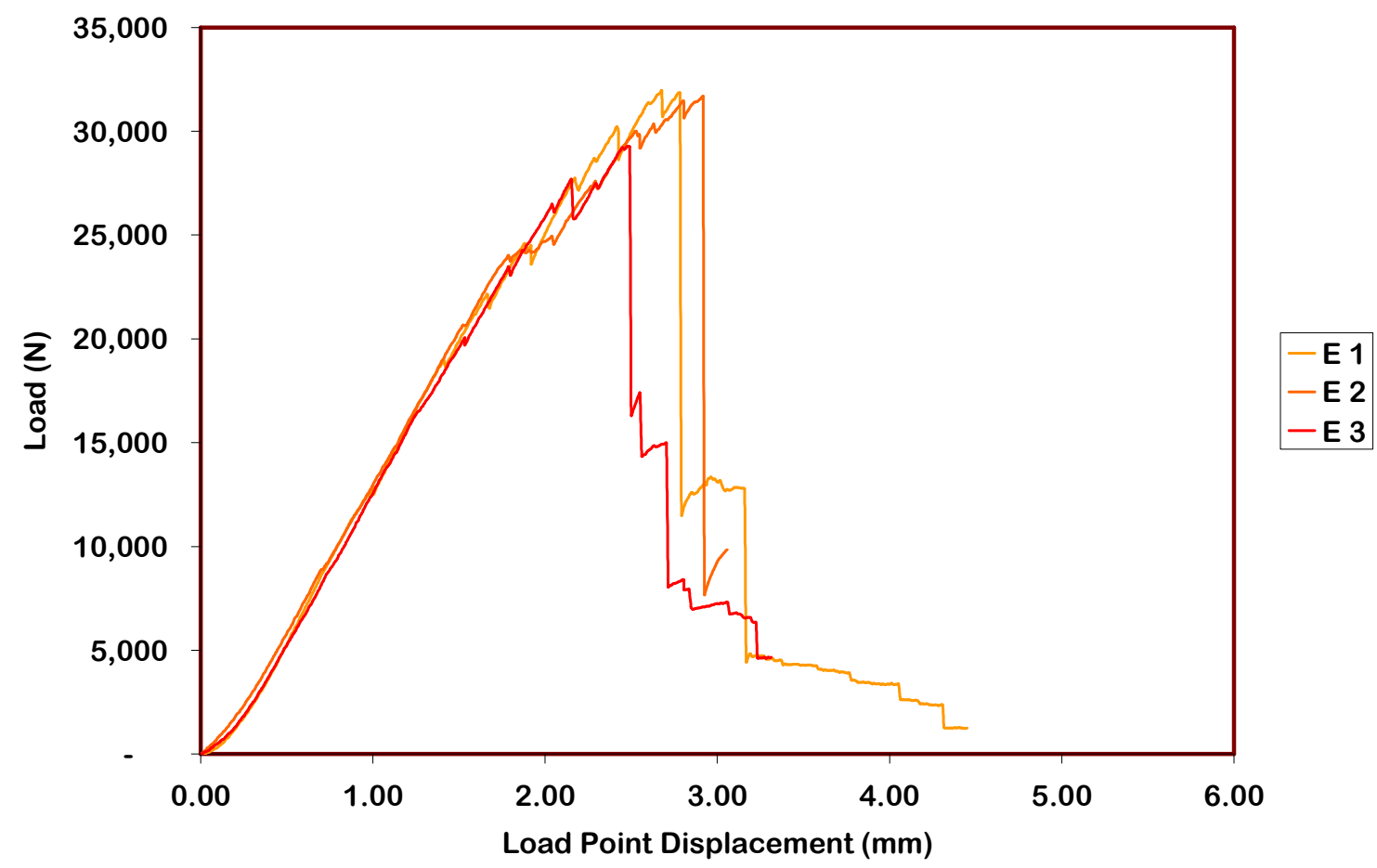

Fig. 7 (d): SENB monotonic fracture tests P- $\Delta$ behavior for Epon

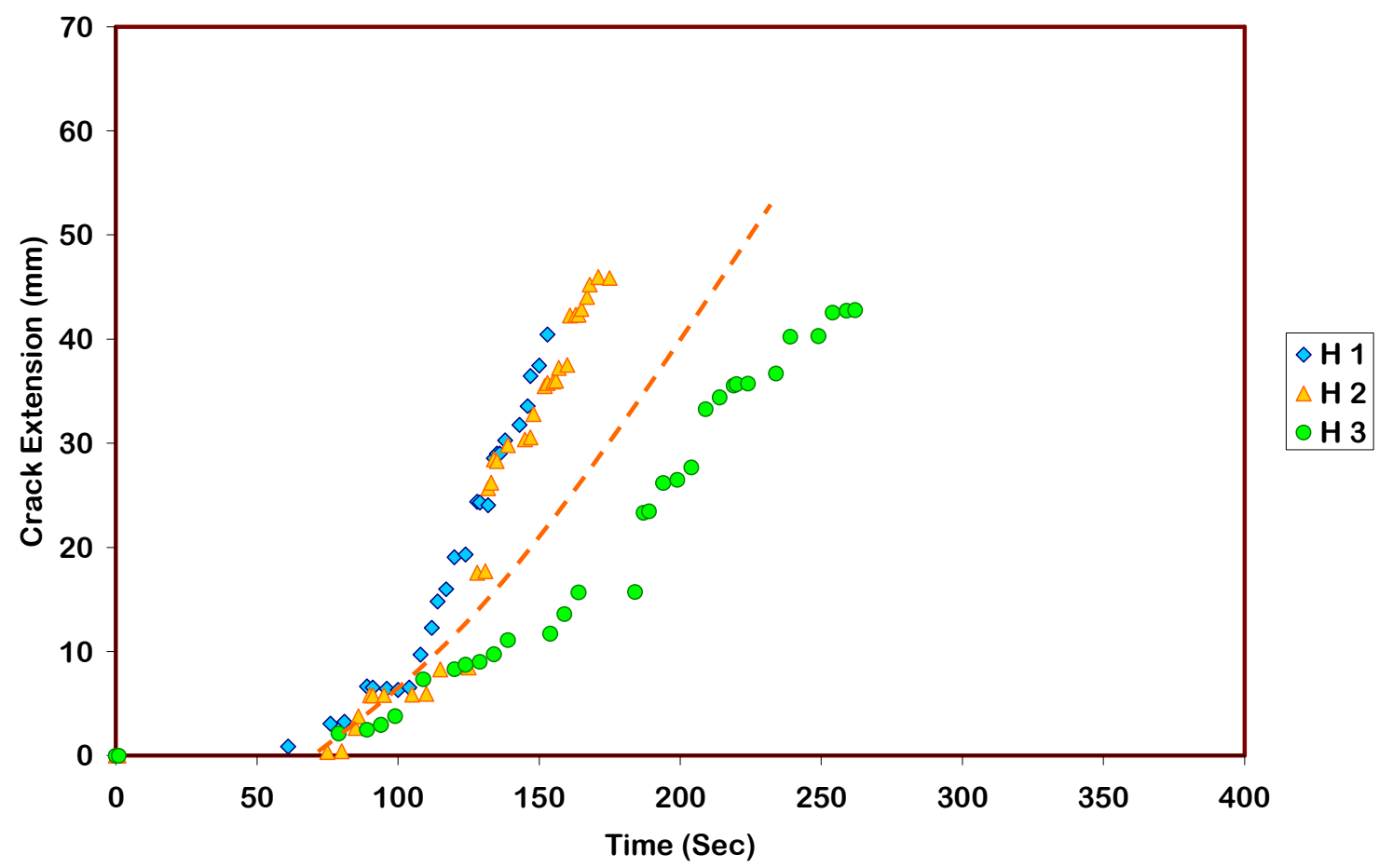

Fig. 7 (e): Crack tip position for Hetron SENB specimens 


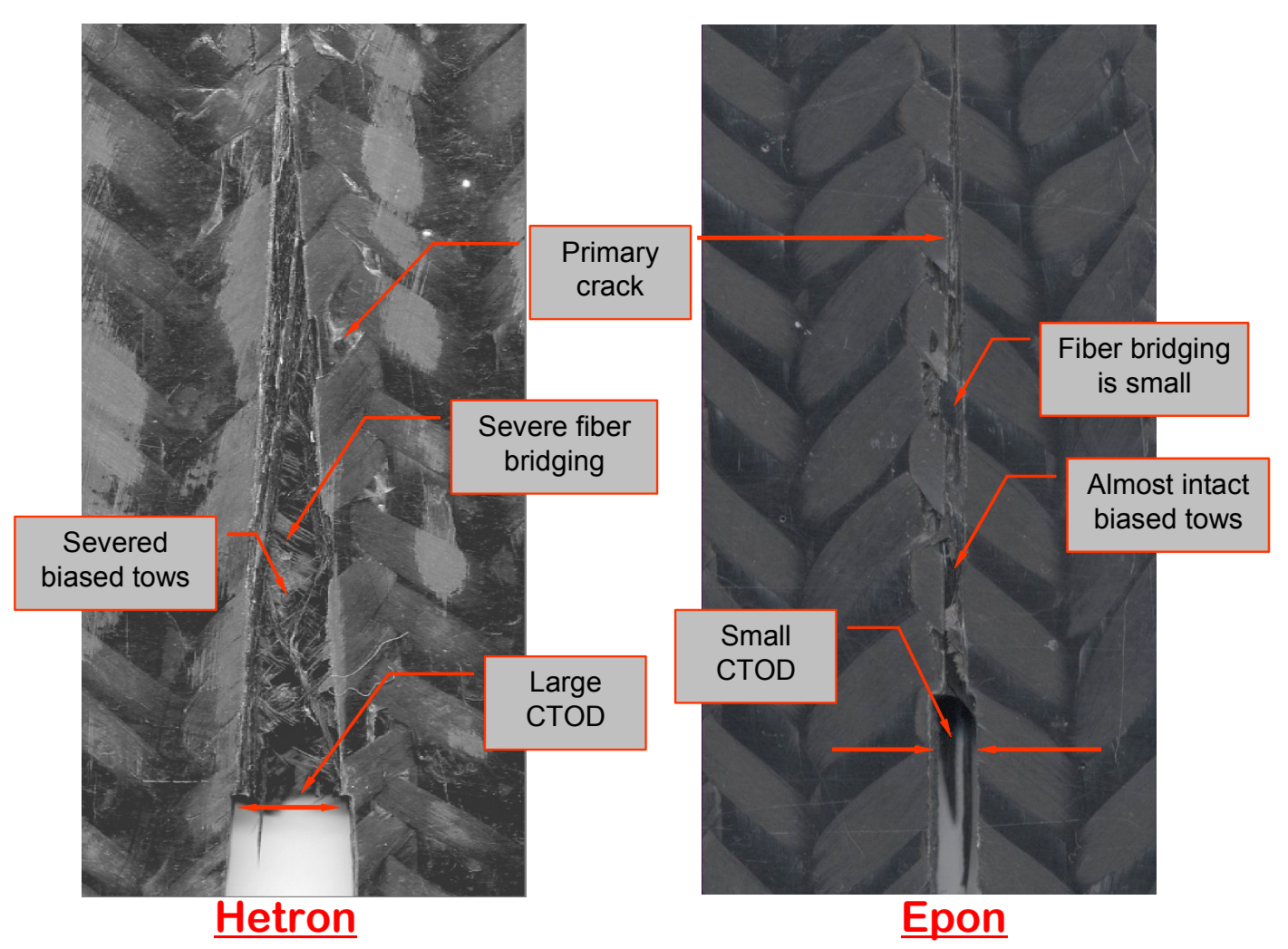

Figure 7 (f): Extent of damage in Hetron and Epon specimens

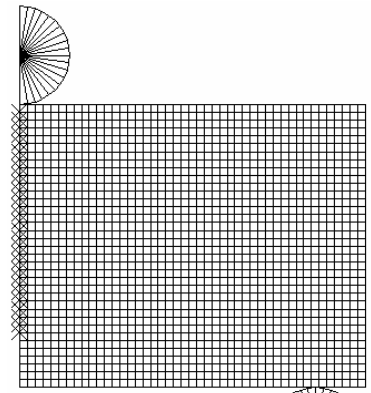

(a)

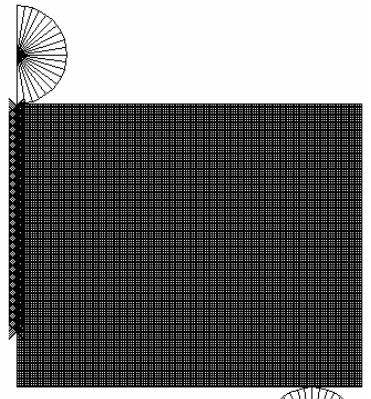

(c)

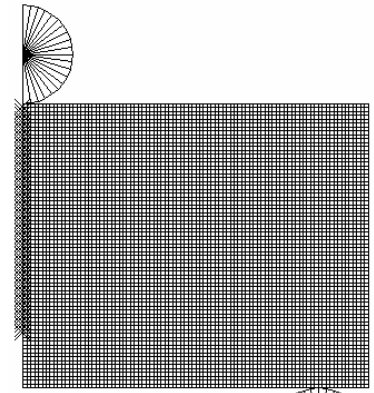

(b)
Case A 1610 elements Case B 6570 elements Case C 26280 elements

Figure 8 (a): Three FEA meshes with different element density 


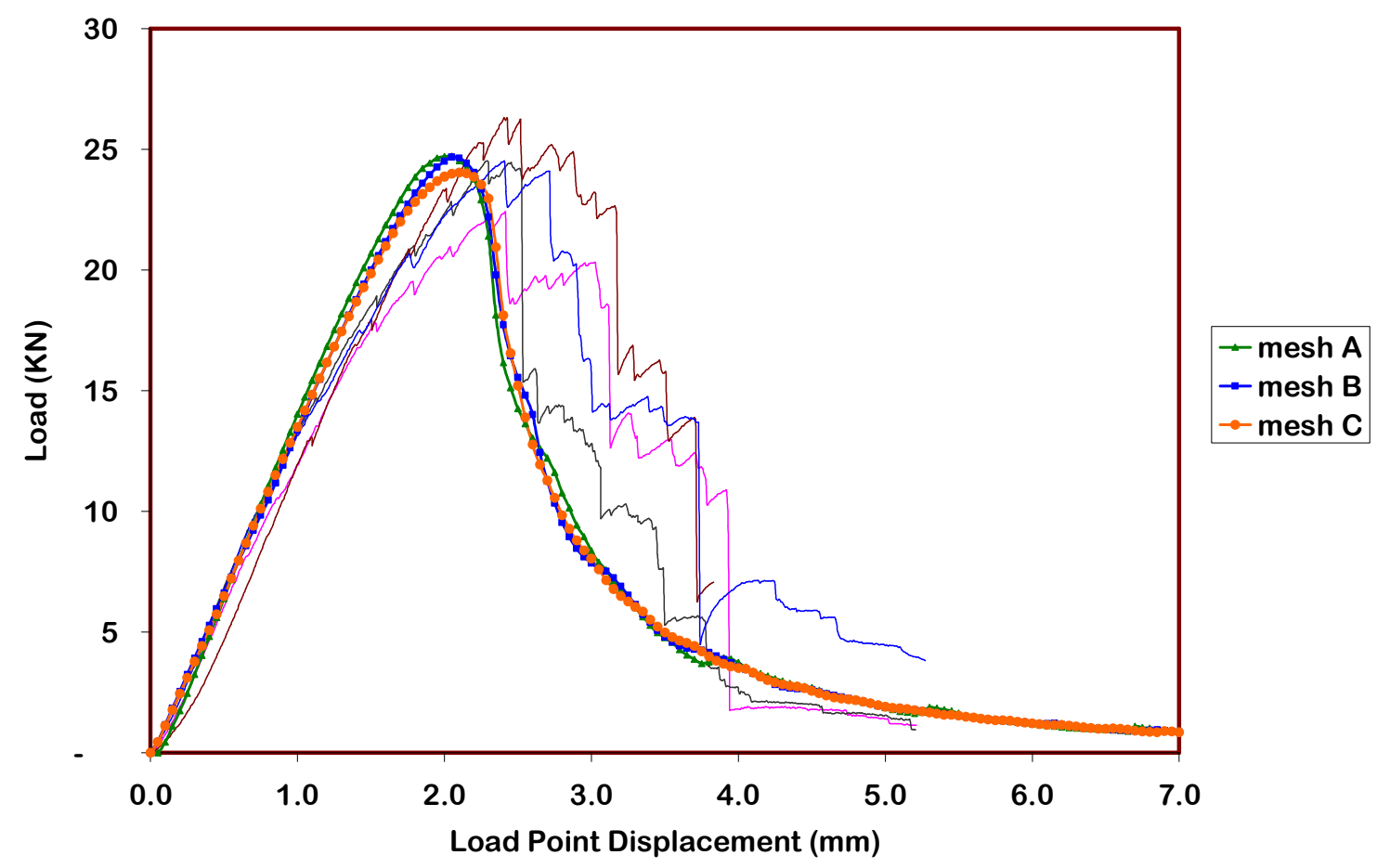

Figure 8 (b): Comparison between experiments and DCZM for Hetron

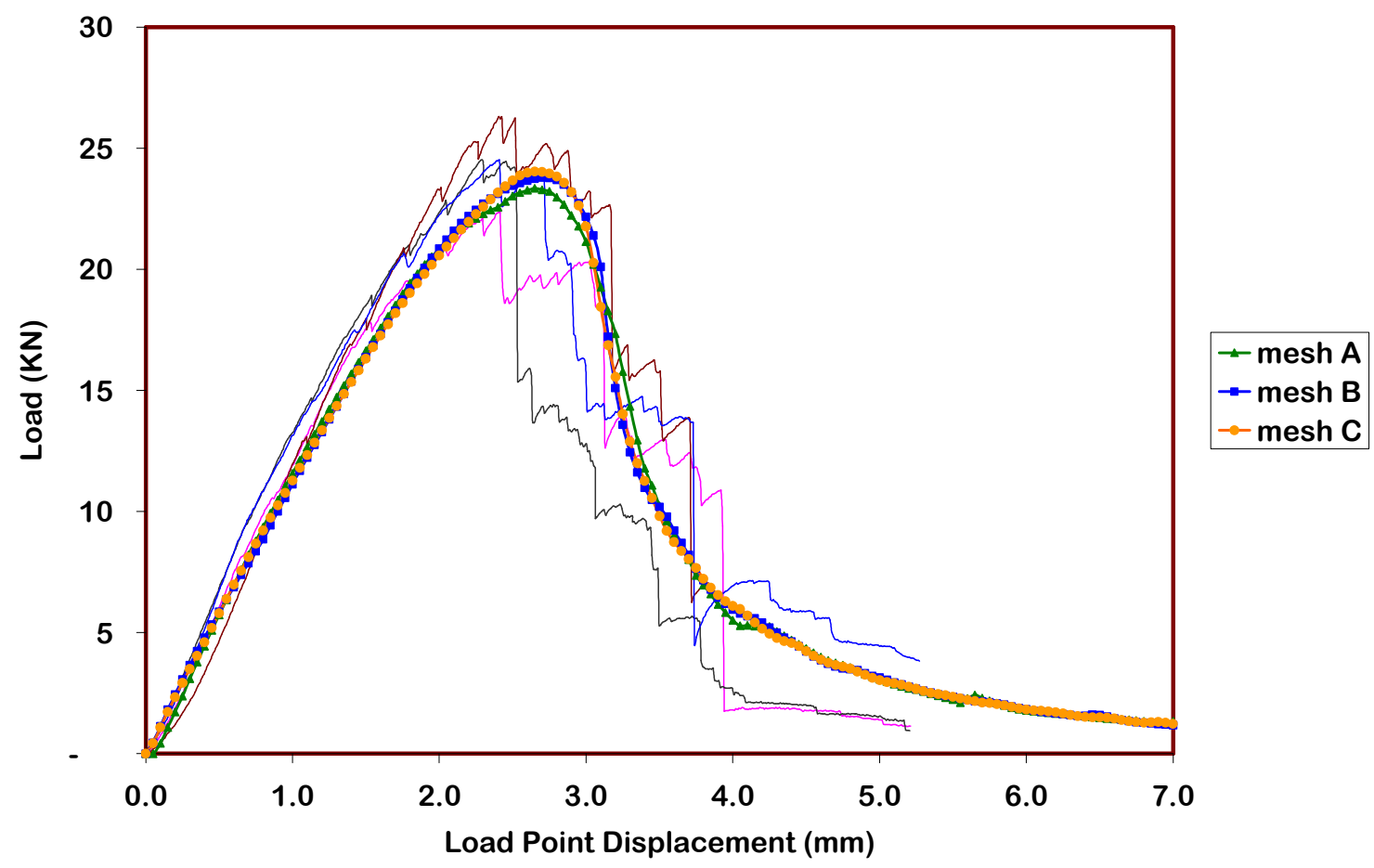

Figure 8 (c): Comparison between test experiments and DCZM with plasticity for Hetron 


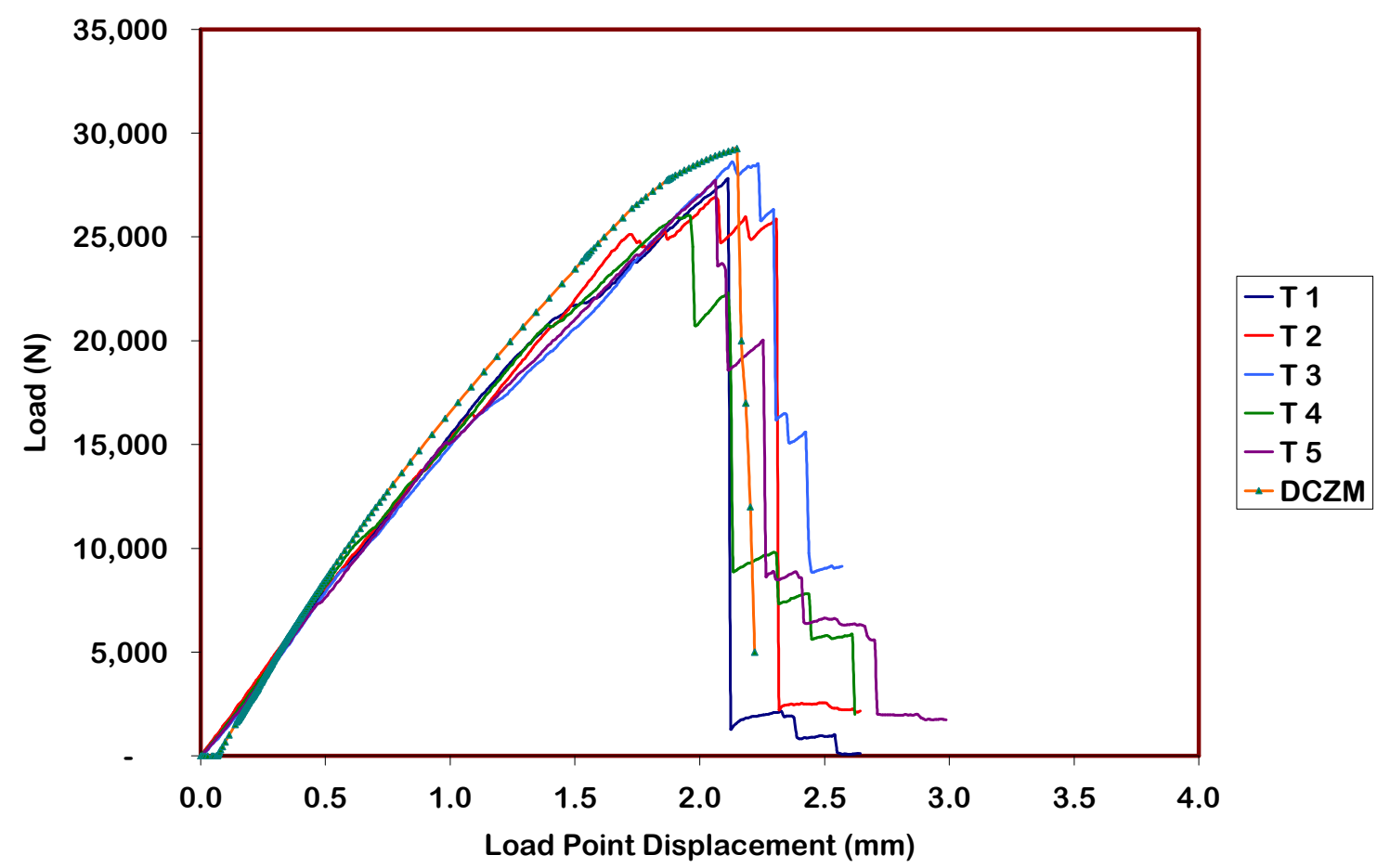

Figure 8 (d): Comparison between test experiments and DCZM with plasticity for Epon 